ARTICLE

https://doi.org/10.1038/s41467-019-11230-9

\title{
Bacterial outer membrane proteins assemble via asymmetric interactions with the BamA $\beta$-barrel
}

\author{
Matthew T. Doyle ${ }^{1}{ }^{1} \&$ Harris D. Bernstein ${ }^{1}$
}

The integration of $\beta$-barrel proteins into the bacterial outer membrane (OM) is catalysed by the $\beta$-barrel assembly machinery (BAM). The central BAM subunit (BamA) itself contains a $\beta$-barrel domain that is essential for OM protein biogenesis, but its mechanism of action is unknown. To elucidate its function, here we develop a method to trap a native Escherichia coli $\beta$-barrel protein bound stably to BamA at a late stage of assembly in vivo. Using disulfidebond crosslinking, we find that the first $\beta$-strand of a laterally 'open' form of the BamA $\beta$ barrel forms a rigid interface with the C-terminal $\beta$-strand of the substrate. In contrast, the lipid-facing surface of the last two BamA $\beta$-strands forms weaker, conformationally heterogeneous interactions with the first $\beta$-strand of the substrate that likely represent intermediate assembly states. Based on our results, we propose that BamA promotes the membrane integration of partially folded $\beta$-barrels by a 'swing' mechanism.

\footnotetext{
${ }^{1}$ Genetics and Biochemistry Branch, National Institute of Diabetes and Digestive and Kidney Diseases, National Institutes of Health, Bethesda, MD 20892,

USA. Correspondence and requests for materials should be addressed to H.D.B. (email: harris_bernstein@nih.gov)
} 
T he outer membrane (OM) of Gram-negative bacteria is a key load-bearing structure ${ }^{1}$ that is densely packed with proteins ${ }^{2}$. Integral outer membrane proteins (OMPs) serve multiple critical cellular functions, including nutrient uptake ${ }^{3}$, protein secretion ${ }^{4,5}$ and adhesion ${ }^{6}$. Almost all of these proteins are anchored to the OM by a unique ' $\beta$-barrel' structure. OMP $\beta$ barrels form closed antiparallel $\beta$-sheets held together by hydrogen bonds between the first $\beta$-strand and a conserved C-terminal $\beta$-strand (the ' $\beta$-signal') that create a ' $\beta$-seam'7-9 (Fig. 1a, top). The result is a highly stable amphipathic structure ranging in size from 8 to $36 \beta$-strands with alternating hydrophobic lipid-facing and hydrophilic lumen-facing residues. Some OMPs contain separately folded extracellular or periplasmic domains or segments that are embedded inside the $\beta$-barrel ${ }^{10}$. Proteins that have a $\beta$-barrel architecture are also found in the $\mathrm{OM}$ of organelles of bacterial origin including mitochondria and chloroplasts ${ }^{11,12}$.

Once OMPs are translocated across the inner membrane by the Sec-translocon and maintained in an assembly-competent state by periplasmic chaperones, they are assembled and integrated into the $\mathrm{OM}$ in the absence of external energy inputs ${ }^{13}$. This is achieved by the $\beta$-barrel assembly machinery (BAM), which in $E$. coli is composed of a $\beta$-barrel protein (BamA) and four accessory lipoproteins (BamBCDE) that associate with the periplasmic POTRA (polypeptide transport-associated) domains of $\mathrm{BamA}^{14}$. Both BamA and BamD are conserved and essential for viability 15,16 , while $\operatorname{bamB}, \operatorname{bam} C$ and bamE mutants produce variable OMP assembly defects ${ }^{10}$. BamA is a member of the Omp85 superfamily, a group of 16 -stranded $\beta$-barrel proteins that
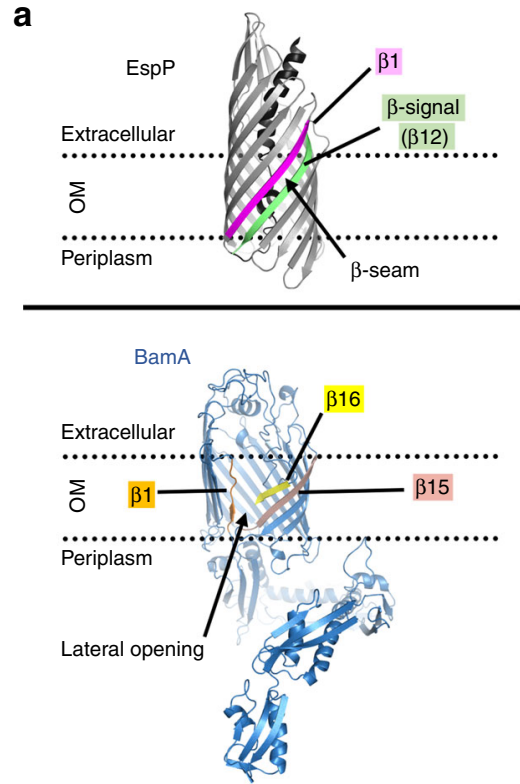

d
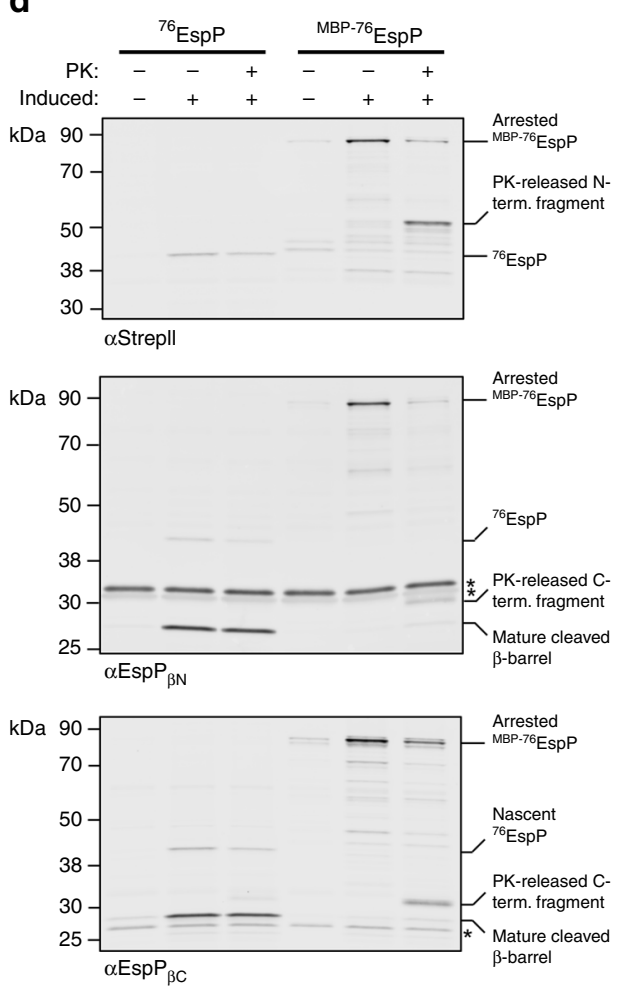

C b

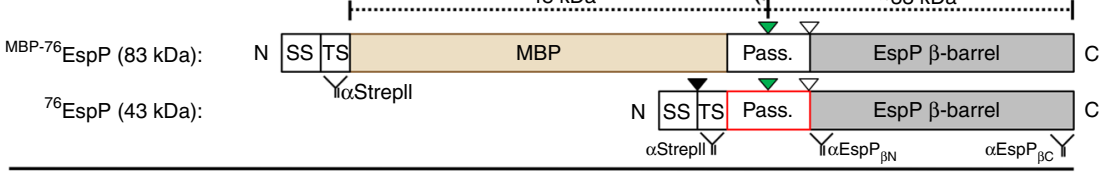

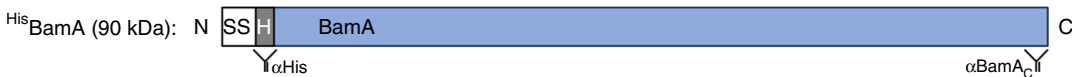

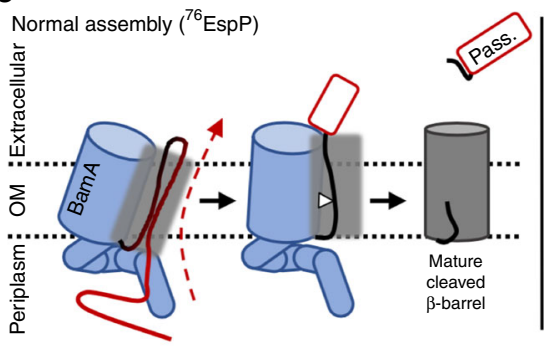

Arrest-release assembly $\left({ }^{\mathrm{MBP}-76} \mathrm{EspP}\right)$

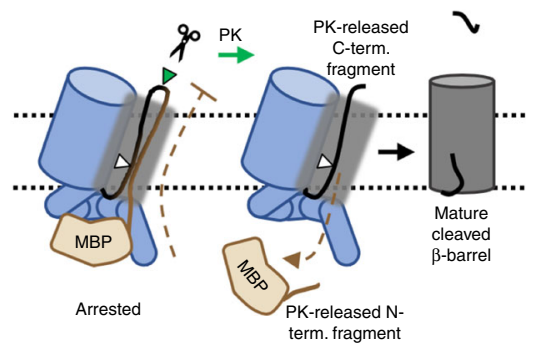

$\mathbf{e}$
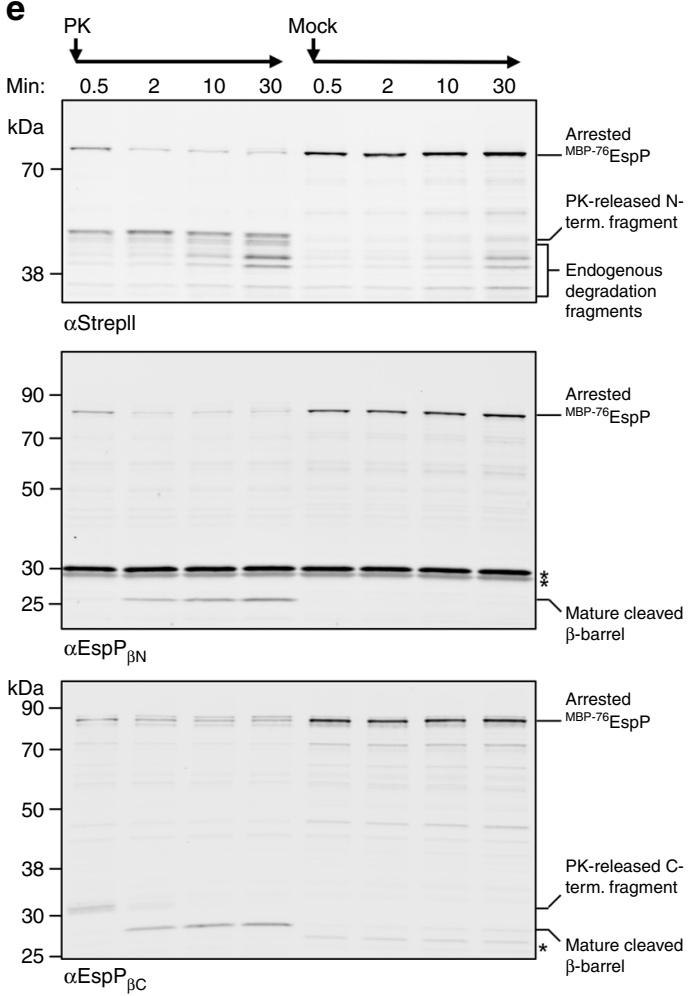

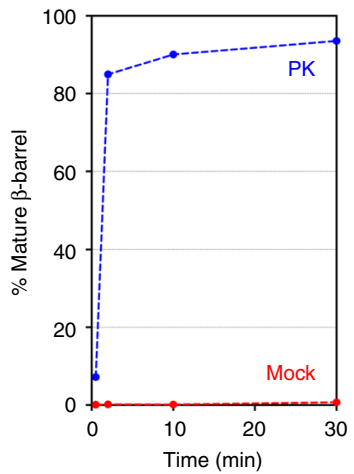


Fig. $1 \mathrm{MBP}-76 \mathrm{EspP}$ forms a stable OMP assembly intermediate in vivo. a Top, Crystal structure of the EspP $\beta$-barrel and embedded linker (PDB id: 3 slj) 42 . The $\beta$-seam between $\beta$-strand 1 (magenta) and the $C$-terminal $\beta$-signal stand (green, $\beta$-stand 12) is shown. Bottom, Structure of BamA derived from the cryo-EM structure of the BAM holocomplex (PDB id: 5 ljo) 21 . The lateral opening between $\beta$-strand 1 (orange) and $\beta$-strands 15 (salmon) and 16 (yellow) is shown. b Primary structures of MBP-76 EspP, ${ }^{76} \mathrm{EspP}$ and His BamA. SS: signal sequence; TS: TwinStrepll-tag; MBP: maltose-binding protein; Pass.: passenger domain, PK: proteinase $\mathrm{K} ; \mathrm{H}$ : His 8 tag. Green and white triangles show the location of the surface-exposed loop cleaved by PK and the native intra-barrel cleavage site, respectively. The binding sites of antibodies/antisera used throughout this study are indicated. c Model depicting the normal assembly of ${ }^{76} \mathrm{EspP}$ (left) and 'arrest-release' assembly of $\mathrm{MBP}-76 \mathrm{EspP}$ (right). During the assembly of ${ }^{76} \mathrm{EspP}$, the passenger domain is secreted in a C-to N-terminal direction while the $\beta$-barrel is bound to BamA. Although the translocation of the MBP-76EspP passenger domain is initiated properly, the MBP moiety stalls translocation and traps the $\beta$-barrel in association with BamA. Assembly can be restarted by adding PK to release an $\mathrm{N}$-terminal fragment that contains the MBP moiety. d E. coli BL21(DE3) were transformed with either pMTD607/pMTD372 or pMTD826/pMTD372, and ${ }^{76}$ EspP or MBP-76EspP was expressed with His BamABCDE under optimised conditions (see Supplementary Fig. 1). Cells were PK-treated or mock-treated on ice. Immunoblots were then conducted using the indicated antibodies/antisera. A cross-reactive protein is denoted ( $\left.{ }^{\star}\right)$. e Reactivation of MBP-76 EspP assembly ('arrest-release'). BL21 (DE3) that expressed MBP-76EspP and HisBamABCDE were treated with PK (or mock-treated) over a 30 min time course at $25^{\circ} \mathrm{C}$. Immunoblots were then conducted using the indicated antibodies/antisera. Cross-reactive proteins are denoted $\left(^{\star}\right)$. The fraction of the MBP-76 EspP that was completely assembled (\% mature $\beta$-barrel) was calculated using the blot that was probed with $\alpha \operatorname{EspP}_{\beta \mathrm{N}}$. Representative results from at least two independent experiments are shown in d, e. Source data are provided as a Source Data file

have been implicated in both membrane protein insertion and protein secretion reactions in bacteria and organelles ${ }^{17,18}$.

Despite multiple solved structures ${ }^{19-21}$, how BAM interacts with client $\beta$-barrel proteins to catalyse assembly remains the most pressing question in OMP biogenesis ${ }^{13}$. Two frontrunning models of OMP assembly, the 'threading' model (also known as the 'budding' model) and the 'assisted' model, centre on evidence that the seam between the first and last $\beta$-strands of the BamA $\beta$ barrel ( $\beta 1$ and $\beta 16)$ is structurally unstable and can open laterally (Fig. 1a, bottom). Indeed, the introduction of disulfide-bonds into BamA that prevent lateral opening of the $\beta$-barrel creates a lethal phenotype $^{20,22}$ and inhibits OMP assembly in vitro ${ }^{21}$. In the threading model, the $\beta$-strands of unfolded OMPs are threaded through the BamA $\beta$-barrel lumen and inserted sequentially into the plane of the OM through the lateral opening (the lateral 'gate') in BamA ${ }^{22-24}$. A hybrid-barrel is created during the assembly process that collapses when folding is complete. This model is supported by recent evidence that the mitochondrial homolog of BamA, Sam50, forms two aligned interfaces with Cterminal fragments of a mitochondrial $\beta$-barrel protein in isolated mitochondria ${ }^{18}$. The discovery of interactions between the $\mathrm{C}$ terminal $\beta$-strand of the substrate and Sam50 $\beta 1$, and the Nterminal $\beta$-strand of the substrate and Sam $50 \beta 16$, led to the proposal that insertion involves the binding of the $\beta$-signal to Sam $\beta 1$, the opening and expansion of the lateral gate to accommodate an increasing number of $\beta$-hairpins, and the eventual release of the full-length protein into the lipid bilayer. The assisted model posits that the combined effects of the wedgeshape of BamA and dynamics of BamA $\beta 16$ cause membrane disruption and lower the energy barrier for integration of prefolded OMPs ${ }^{24-26}$. This model is supported by evidence that OMPs begin to fold in the periplasm prior to integration ${ }^{27-32}$, that BamA lowers the kinetic barrier for OMP insertion imposed by lipid head groups ${ }^{33}$, and that BamA exerts a greater stimulatory effect on the insertion of OMPs into thicker bilayers ${ }^{34}$. In this model, BamA is more passive, and no specific interactions form between the lateral-opening and the client OMP.

Here, we sought to test these models by probing interactions between BamA and an OMP assembly intermediate in vivo. To this end, we design a method to arrest the assembly of a native $\beta$ barrel while it remains stably bound to BAM. This tool allows us to precisely map interactions between BamA and the client OMP via intermolecular disulfide-bond formation. We find that the BamA $\beta$-barrel forms two dissimilar interfaces with the assembly intermediate that effectively creates a structure that we refer to as an 'asymmetric hybrid-barrel'. This unique structure, however, does not seem to result from the stepwise threading of $\beta$-strands of the client protein from the lumen of the BamA $\beta$-barrel into the OM via a lateral gate. Our results strongly suggest an alternative model for BamA function in which it facilitates the transfer of partially folded $\beta$-barrels from the periplasm into the OM. This model accounts for the results of previous studies but differs considerably from both the 'threading' and 'assisted' models.

\section{Results}

Design of a stable OMP assembly intermediate bound to BamA. To further test the mechanism of BAM-mediated membrane integration of $\beta$-barrel proteins, we sought to obtain a detailed map of interactions between BamA and a stable OMP assembly intermediate in vivo. Because most OMPs are assembled rapidly in living cells, it is challenging to isolate a native $\beta$-barrel that is stably bound to BAM at a specific stage of assembly. To overcome this problem, we exploited the unique features of 'autotransporters', a class of OMPs that contain an N-terminal extracellular ('passenger') domain in addition to an average size 12 -stranded C-terminal $\beta$-barrel domain ${ }^{35}$. Autotransporter $\beta$ barrel domains are not completely assembled and released from BAM until the passenger domain, which is translocated across the $\mathrm{OM}$ in a $\mathrm{C}$ - to $\mathrm{N}$-terminal direction via the formation of an intrabarrel hairpin, is fully secreted ${ }^{27,36,37}$. Nevertheless, almost the entire passenger domain can be deleted or replaced by heterologous polypeptides without affecting $\beta$-barrel assembly $34,38,39$ Based on evidence that the translocation of fully folded heterologous polypeptides by autotransporters is often limited by their $\operatorname{size}^{38,39}$, we hypothesised that the fusion of a large protein to the passenger domain would create a molecular 'knot-in-a-rope' that arrests assembly after the association of the $\beta$-barrel domain with BAM and the initiation of translocation. To test this idea we fused the $40 \mathrm{kDa}$ maltose-binding protein (MBP), which normally folds rapidly in the periplasm, to several N-terminally truncated versions of the E. coli O157:H7 autotransporter EspP (Fig. 1b). We chose EspP because the two domains of the protein are separated in an autocatalytic intra-barrel cleavage reaction following the completion of $\beta$-barrel assembly ${ }^{40}$ (Fig. 1c, left). This cleavage reaction provides an important internal control that enabled us to easily monitor the assembly status of the fusion proteins. Additionally, many aspects of the assembly of EspP have been characterised $^{27,28,30,34,36,41}$ and the crystal structure of its $\beta$-barrel domain has been solved ${ }^{40,42}$.

Consistent with our hypothesis, we found that the MBP-EspP fusions caused assembly arrest after the fusion proteins were targeted to the OM. E. coli were transformed with a low-copy plasmid encoding TwinStrepII-tagged MBP-EspP fusions 
controlled by the rha promoter ${ }^{43}$ and a second plasmid encoding BAM with a His-tagged copy of BamA controlled by an IPTGinducible promoter ${ }^{41}$ (Fig. 1b). In trial experiments we tested the assembly of fusion proteins that contained passenger domain fragments ('linkers') of varied lengths $(115,97,76$, or 59aa) between MBP and the $\beta$-barrel domain. The absence of the cleaved $\beta$-barrel domain on immunoblots showed that none of the fusion proteins were able to assemble completely (Supplementary Fig. 1a, left). If the fusion proteins were targeted to BAM and passenger domain translocation was initiated, we predicted that the linkers would be exposed on the cell surface in a hairpin conformation and subject to cleavage by added proteinase $\mathrm{K}(\mathrm{PK})$ (Fig. 1c, right). As expected, PK digestion released a $\sim 33 \mathrm{kDa} C-$ terminal fragment corresponding to the $\beta$-barrel and a small piece of the linker from all but the smallest fusion protein (Supplementary Fig. 1a, left). PK also released multiple $\sim 50 \mathrm{kD}$ $\mathrm{N}$-terminal fragments from the two largest fusion proteins that were detected on immunoblots with an anti-StrepII antibody, but only a single $\mathrm{N}$-terminal fragment from the fusion containing the 76aa-linker. Furthermore, only the fusion that contains the 76aalinker was resistant to cleavage by endogenous periplasmic proteases. This observation plus the presence of a single $\mathrm{N}$ terminal PK fragment indicates that the fusion is stably trapped at a specific stage of assembly in which the folded MBP moiety remains close to the OM after it reaches BAM (Supplementary Fig. 1a, right). We therefore performed all further experiments with this fusion, which we refer to as $\mathrm{MBP}-76 \mathrm{EspP}$. Note that the final version of $\mathrm{MBP}-76 \mathrm{EspP}$ also contains a surface-exposed TEV cleavage-site in the linker (between EspP residues 984/985, Supplementary Fig. 1b) that, while not exploited in this work, is likely to be useful in future studies.

Under optimised ${ }^{\mathrm{MBP}-76} \mathrm{EspP}$ and BAM expression conditions that we used throughout this study (Supplementary Fig. 1c), no mature $\beta$-barrel was detected and most of the fusion protein was cleaved into a C-terminal $\beta$-barrel-containing fragment and an $\mathrm{N}$ terminal MBP-containing fragment (Fig. 1d). This observation shows that the assembly of the majority of MBP-76EspP was stably arrested at steady-state. Under the same conditions, a control protein that lacked the MBP moiety, ${ }^{76} \mathrm{EspP}$, was almost all detected as mature $\beta$-barrel due to normal rapid assembly (Fig. 1b, d).

If the assembly of $\mathrm{MBP}-76 \mathrm{EspP}$ can be restarted after passenger domain translocation stalls, we expected that PK treatment would cleave the surface-exposed loop of the fusion protein, and that the subsequent release of the MBP moiety into the periplasm would facilitate the completion of assembly (Fig. 1c, right). Strikingly, after cells were incubated with $\mathrm{PK}$ at $25^{\circ} \mathrm{C}, \sim 90 \%$ of the fusion protein was fully assembled within $10 \mathrm{~min}$ as indicated by the accumulation of the mature $\beta$-barrel domain (Fig. 1e). In contrast, $\mathrm{MBP}-76 \mathrm{EspP}$ in mock-treated cells remained stable (Fig. 1e). Therefore, arrested MBP-76EspP does not fall into a non-productive pathway, but remains in an assembly-competent state that conserves interactions with BAM that occur during normal assembly.

A stable $\beta$-seam forms between $\operatorname{BamA}(\beta 1)$ and $M B P-76$ EspP $(\boldsymbol{\beta} 12)$. Having established a model system in which the assembly of a $\beta$-barrel protein arrests stably and reversibly, we were able to begin to precisely map interactions between the arrested MBP $-{ }^{76}$ EspP assembly intermediate and BAM subunits. Although no direct evidence exists, it has been proposed that the conserved final strand of OMPs, the $\beta$-signal, interacts with BamA during assembly ${ }^{13,44,45}$. Based on a recent analysis of interactions between Sam 50 and truncated forms of a mitochondrial outer membrane $\beta$-barrel in isolated mitochondria ${ }^{18}$, we hypothesised that $\operatorname{BamA} \beta$-strand $1[\operatorname{BamA}(\beta 1)]$ interacts with the $\beta$-signal of $\mathrm{MBP}-{ }^{76} \mathrm{EspP}[\mathrm{MBP}-76 \mathrm{EspP}(\beta 12)]$. To test this, we used solved structures of $\mathrm{BamA}^{19-21}$ and the EspP $\beta$-barrel ${ }^{40,42}$ as a guide to replace pairs of aligned ${ }^{\operatorname{His}} \operatorname{BamA}(\beta 1)$ and $\mathrm{MBP}-76 \mathrm{EspP}(\beta 12)$ residues with cysteine (Fig. $2 \mathrm{a})$. We then expressed the modified $\mathrm{MBP}-76 \mathrm{EspP}(\beta 12)$ and BAM, and assessed intermolecular proximity by disulfide-bond formation in vivo after the addition of the thiol-specific oxidiser 4-DPS. In these experiments we retained the two native cysteine residues in BamA loop 6 (C690 and C700) that normally form an intramolecular disulfide-bond ${ }^{46}$. We found that these residues are important for loop 6 to fold into a native conformation but do not interfere with intermolecular disulfidebond formation (Supplementary Fig. 2).

Consistent with our hypothesis, we observed remarkable levels of disulfide-bond formation between aligned lumen-facing cysteines in ${ }^{\mathrm{MBP}}-{ }^{76} \mathrm{EspP}(\beta 12)$ and ${ }^{\mathrm{His}} \mathrm{BamA}(\beta 1)$. After the addition

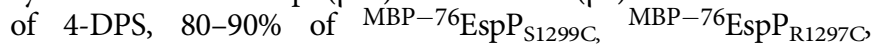
${ }^{\mathrm{MBP}-76} \mathrm{EspP}_{\mathrm{N} 1295 \mathrm{C}}$ and ${ }^{\mathrm{MBP}-76} \mathrm{EspP}_{\mathrm{N} 1293 \mathrm{C}}$ formed high molecularweight adducts with ${ }^{\mathrm{His}} \mathrm{BamA}_{\mathrm{S} 425 \mathrm{C}}$, HisBamA ${ }_{\mathrm{N} 427 \mathrm{C}}$, ${ }^{\mathrm{His}} \mathrm{BamA}_{\mathrm{G} 429 \mathrm{C}}$, His BamA $A_{\text {G431C }}$, respectively, that were detected by quantitative duplex immunoblots probed with both anti-StrepII and anti-BamA C-terminal antisera (Fig. 2b, c, Supplementary Fig. 3a). These results, as well as the detection of appreciable levels $(\sim 5-10 \%)$ of spontaneous oxidation in the absence of 4-DPS, suggests the presence of a stable antiparallel inter-barrel interface spanning the $\mathrm{OM}$ when the assembly of ${ }^{\mathrm{MBP}-76} \mathrm{EspP}$ arrests. Importantly, the observation that the assembly of oxidised $\mathrm{MBP}-76 \mathrm{EspP}$ adducts was completed upon release of the MBP-containing fragment by $\mathrm{PK}$ digestion and subsequent disulfide-bond reduction at $25^{\circ} \mathrm{C}$ (Supplementary Fig. 4) confirms that the adducts remained assembly competent.

We next obtained evidence that $\mathrm{MBP}-{ }^{76} \operatorname{EspP}(\beta 12)$ and His$\operatorname{BamA}(\beta 1)$ form a rigid, non-sliding interface during assembly. We found that distally located cysteine-pairs $\mathrm{MBP}-{ }^{76} \mathrm{EspP}_{\mathrm{N} 1293 \mathrm{C}}$ ${ }^{H i s} B_{\text {BamA }} \mathrm{S}_{425 \mathrm{C}}$ and $\mathrm{MBP}-76 \mathrm{EspP}_{\mathrm{S} 1299 \mathrm{C}} /{ }^{\mathrm{His}} \mathrm{BamA}_{\mathrm{G} 431 \mathrm{C}}$ failed to form adducts and that disulfide-bond formation was severely diminished when the residues were misaligned by only one register (Fig. 2d, Supplementary Fig. 3b). We also did not observe significant interactions between ${ }^{\mathrm{MBP}-76} \mathrm{EspP}(\beta 12)$ and His $\mathrm{BamA}$ $(\beta 2), M B P-76 \operatorname{EspP}(\beta 12)$ and ${ }^{H i s} \operatorname{BamA}(\beta 15 / \beta 16)$, or ${ }^{\mathrm{MBP}-76} \mathrm{EspP}$ $(\beta 1)$ and ${ }^{H i s} \operatorname{BamA}(\beta 1)$ (Supplementary Figs. 3d and 5). Because luminal residues in the mature EspP $\beta$-barrel cannot form intermolecular disulfide-bonds ${ }^{40}$, these results strongly suggest that both $\beta$-barrels are in an 'open' state when $\mathrm{MBP}-76 \mathrm{EspP}(\beta 12)$ and ${ }^{H i s} \operatorname{BamA}(\beta 1)$ interact. Furthermore, when we co-expressed opposite-oriented (luminal vs. lipid-facing) cysteine-pairs to probe the flexibility and secondary structure of the interface, chemically oxidised disulfide-bond levels were typically low $(\sim 5 \%)$ and no significant spontaneous disulfide-bond was observed (Fig. 2c, e, Supplementary Fig. 3c). The results indicate that there is considerable rigidity between $\mathrm{MBP}-{ }^{76} \mathrm{EspP}(\beta 12)$ and His $\mathrm{BamA}(\beta 1)$. A higher level of disulfide-bond formation between

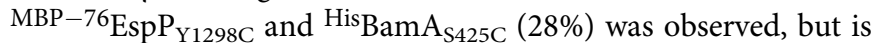
likely explained by the localisation of $\mathrm{BamA}_{\mathrm{S} 425}$ near a known flexible-hinge between the BamA $\beta$-barrel and periplasmic POTRA domains ${ }^{47}$.

A conformationally diverse second inter-barrel interface. A recent examination of interactions between Sam50 and fragments of mitochondrial outer membrane $\beta$-barrels showed that a potentially strong second interface forms between the final $\beta$ strand of Sam50 [Sam50( $\beta 16)]$ and the N-terminal $\beta$-strand of the client, and suggested that an expanding $\beta$-sheet enters the OM via the lumen of Sam $50^{18}$. To determine if a similar second 
a
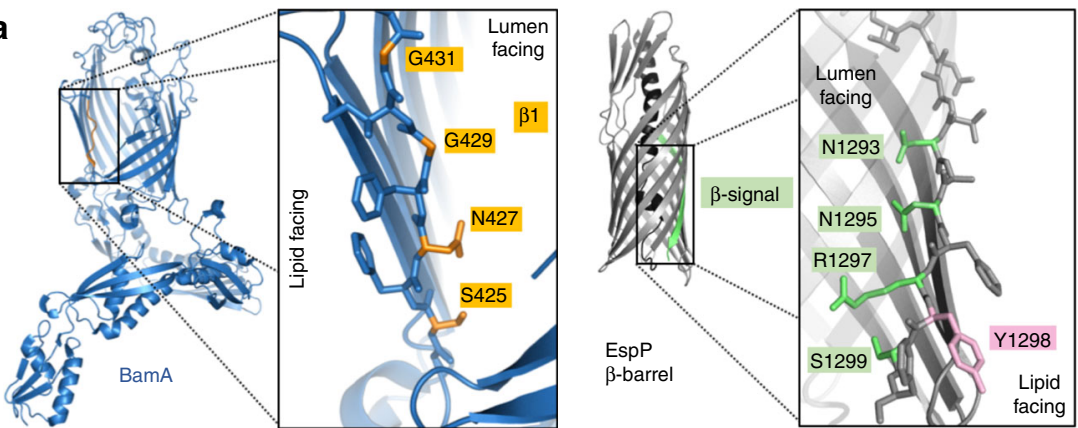

b

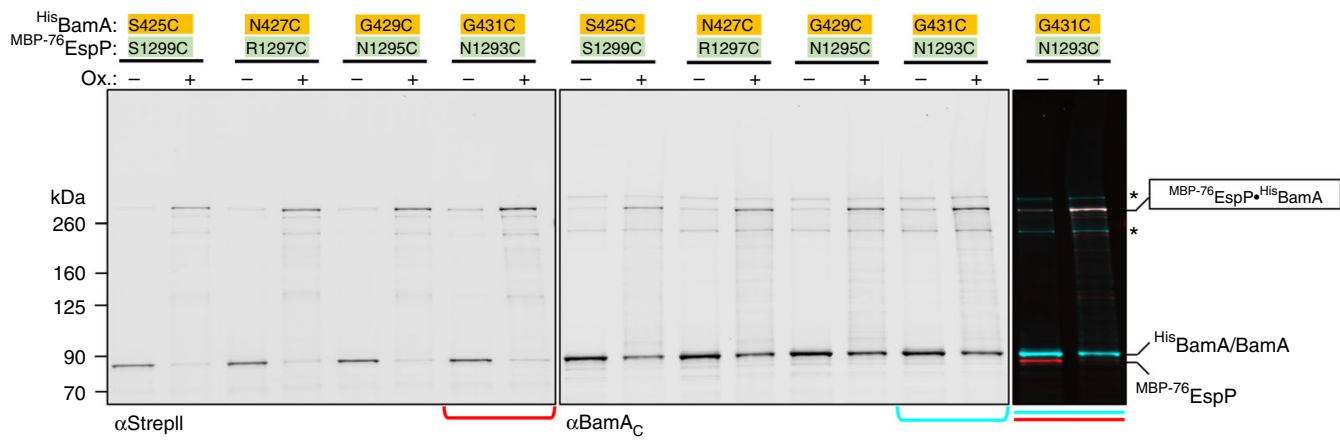

c
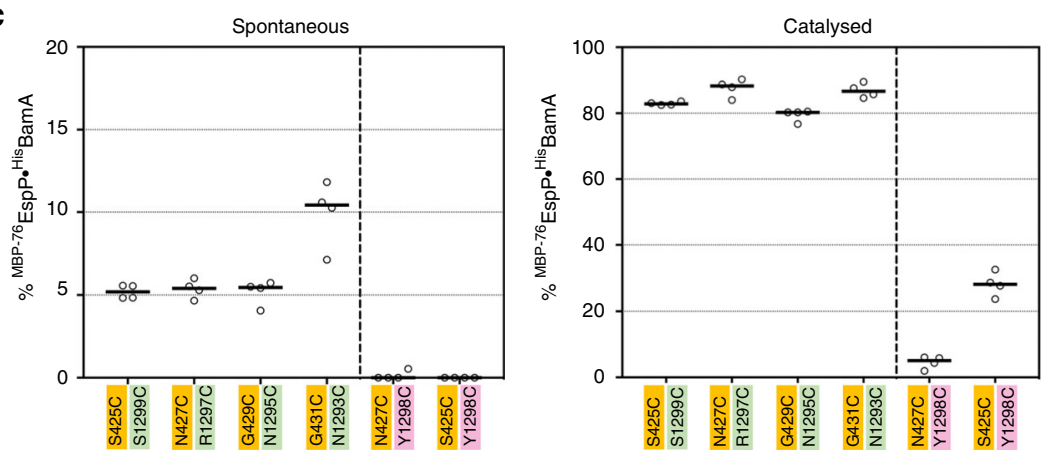

d
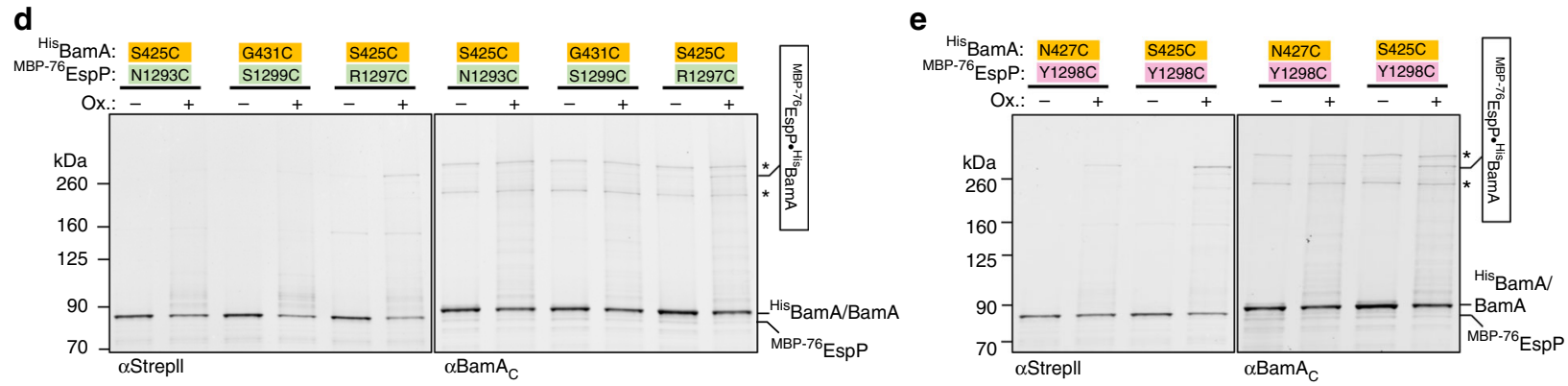

Fig. 2 During assembly the MBP-76EspP( $\beta 1) \beta$-signal forms a stable antiparallel seam with $\operatorname{Bam} A(\beta 1)$. a Luminal residues in $B a m A(\beta 1)$ (orange), and luminal and lipid-facing residues in $\mathrm{MBP}-76 \mathrm{EspP}(\beta 12)$ (green and pink, respectively) are shown. Foreground strands of the MBP-76 EspP $\beta$-barrel are transparent in the zoom box. The 'luminal' and 'lipid-facing' designations are based on the orientation of the residues in solved structures (5ljo, 5d0o, and 3slj) ${ }^{20,21,42}$. The BamA and EspP residue numbers are based on their position in the native protein sequence. $\mathbf{b}$ BL21(DE3) that expressed $\mathrm{MBP}-76 \mathrm{EspP}$ with single cysteine substitutions at a luminal positions in $\beta 12$ and HisBamABCDE with cysteine substitutions at a lumen-facing positions in His BamA( $\beta 1)$ were mock-treated ( - ) or treated with 4-DPS $(+)$. Duplex-immunoblots were then conducted using antibodies/antisera against the N-terminus of MBP-76EspP $(\alpha S t r e p l l$, red) and the $\mathrm{C}$-terminus of His BamA/BamA ( $\alpha$ BamA $A_{C}$, cyan) to monitor disulfide-bond formation between cysteine pairs in vivo. The signals are overlaid for one

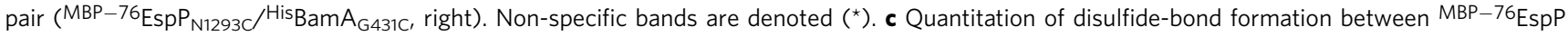
$(\beta 12)-H i s$ BamA( $\beta 1)$ cysteine pairs. Experiments were performed as in $\mathbf{b}$, e (see below) except that only $\alpha$ Strepll was used for probing immunoblots in mocktreated ('spontaneous') and 4-DPS-treated cells ('catalysed'). Bars = median, $N=4$. ANOVA and multiple comparison tests are shown in Supplementary Table 1. $\mathbf{d}$ The experiments shown in $\mathbf{b}$ were repeated, except that misaligned lumen-facing cysteine pairs in $\mathrm{His}_{\mathrm{B} a m A}(\beta 1)$ and $\mathrm{MBP}-76 \mathrm{EspP}(\beta 12)$ were analysed. $\mathbf{e}$ The experiments shown in $\mathbf{b}$ were repeated, except that lumen-facing cysteine positions in HisBamA( $\beta 1)$ and lipid-facing cysteine positions in $\mathrm{MBP}-76 \mathrm{EspP}(\beta 12)$ were analysed. Data are representative of at least two independent experiments for $\mathbf{b}, \mathbf{d}$ and $\mathbf{e}$. Source data are provided as a Source Data file 
a

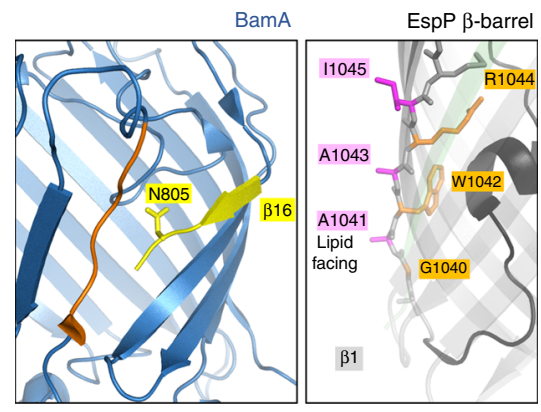

b

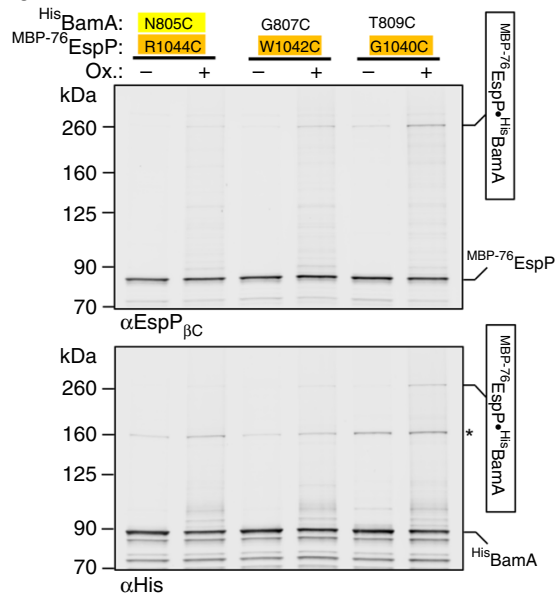

C

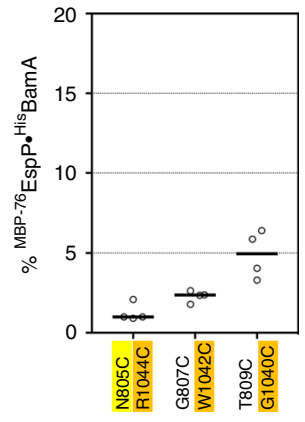

Fig. $3 \mathrm{MBP}-76 \mathrm{EspP}(\beta 1)$ cysteines bond weakly with luminal-facing cysteines in BamA( $\beta 16$ ). a Left, view of BamA showing $\beta$-strand 16 (yellow) and lumenfacing residue $N 805$. Note that the last several residues of $\operatorname{BamA}(\beta 16)$ are not resolved in available structures. Right, view of $M B P-76 \mathrm{Esp} P(\beta 1)$ showing lipid-facing (magenta) and lumen-facing (orange) residues. Foreground strands of the EspP $\beta$-barrel (including $\beta 12$, green) are transparent. $\mathbf{b}$ BL21(DE3) that expressed MBP-76EspP with a cysteine substitution at a luminal position in $\beta 1$ and HisBamABCDE with a cysteine substitution at a luminal position in ${ }^{H i s} \operatorname{BamA}(\beta 16)$ were mock-treated (-) or treated with 4-DPS (+). Duplex-immunoblots were then conducted using antibodies/antisera against the Cterminus of MBP-76 EspP ( $\alpha \mathrm{EspP}_{\beta \mathrm{C}}$ ) and the N-terminus of His BamA ( $\alpha$ His) to monitor disulfide-bond formation between cysteine pairs in vivo. Non-specific bands are denoted $\left({ }^{\star}\right)$. Data are representative of at least two independent experiments. c Quantitation of disulfide-bond formation between MBP-76EspP $(\beta 1)-{ }^{H i s} B a m A(\beta 16)$ cysteine-pairs in cells that were 4-DPS-treated. Experiments were performed as in $\mathbf{b}$ except that only $\alpha$ Strepll was used for probing immunoblots. Bars = median, $N=4$. ANOVA and multiple comparison tests are shown in Supplementary Table 2. Source data are provided as a Source Data file

interface is formed between inward-facing residues of BamA and assembly-arrested $\mathrm{MBP}-76 \mathrm{EspP}$, we introduced cysteines into luminal positions of $\mathrm{His}_{\mathrm{Bam}}(\beta 16)$ and both lumen- and lipidfacing positions in ${ }^{\mathrm{MBP}-76} \mathrm{EspP}(\beta 1)$ (Fig. 3a). As in our analysis of the ${ }^{\mathrm{MBP}-76} \mathrm{EspP}(\beta 12)-{ }^{\mathrm{His}} \mathrm{BamA}(\beta 1)$ interface, we co-expressed cysteine pairs that we posited would be similarly aligned and oriented. However, the luminal residues ${ }^{M B P}-{ }^{76} \mathrm{EspP}_{\mathrm{R} 1044 \mathrm{C}}, \mathrm{MBP}$ ${ }^{-76} \mathrm{EspP}_{\mathrm{W} 1042 \mathrm{C}}$, and ${ }^{\mathrm{MBP}-76} \mathrm{EspP}_{\mathrm{G} 1040 \mathrm{C}}$ displayed only low levels of chemically-induced disulfide-bond formation (1-5\%) with

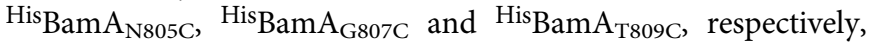
based on quantitative immunoblot analysis (Fig. 3b, c, Supplementary Fig. 6a, b). Even lower levels of interaction were detected when the lipid-facing cysteines ${ }^{M B P}-76{ }^{-} \mathrm{EspP}_{\mathrm{I} 1045 \mathrm{C}}, \mathrm{MBP}^{-76} \mathrm{Esp}-$ $\mathrm{P}_{\mathrm{A} 1043 \mathrm{C}}$ and ${ }^{\mathrm{MBP}-76} \mathrm{EspP}_{\mathrm{A} 1041 \mathrm{C}}$ were paired with ${ }^{\mathrm{His}} \mathrm{BamA}_{\mathrm{N} 805 \mathrm{C}}$,

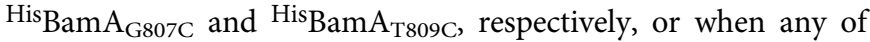
the six ${ }^{\mathrm{MBP}-76} \mathrm{EspP}(\beta 1)$ cysteines were paired in any combination with luminal cysteines in ${ }^{\mathrm{His}} \mathrm{BamA}(\beta 16)$ (Supplementary Fig. 6c-e). Despite the low levels of disulfide-bond formation, ${ }^{H i s} B{ }^{2} A_{T 809 C}$ consistently produced higher adduct levels regardless of the cysteine location in ${ }^{\mathrm{MBP}-76} \mathrm{EspP}(\beta 1)$. This observation implies significant structural promiscuity and is in line with previous reports of dynamicity and kink formation in $\operatorname{Bam} A(\beta 16)^{20,21,25,47}$. Nevertheless, the results strongly suggest that BamA does not form two matching interfaces with client proteins.

A close inspection of the BAM cryo-EM structure ${ }^{21}$ shows that when $\mathrm{BamA}$ is in a 'lateral-open' state, $\operatorname{BamA}(\beta 15)$ and $\mathrm{BamA}$ $(\beta 16)$ are twisted downward towards the periplasm and curled inward towards the $\beta$-barrel lumen. We hypothesised that this unusual conformation might present a unique 'outward-facing' surface that is proximal to the first $\beta$-strand of client $\beta$-barrels. To test this idea, we substituted cysteine for F785 and I806, two outward-facing amino acids in ${ }^{\text {His }} \mathrm{Bam} A(\beta 15)$ and ${ }^{\mathrm{His}} \mathrm{Bam} A(\beta 16)$, respectively, that are predicted to reside at a similar membrane depth, and paired them with $\mathrm{MBP}-76 \mathrm{EspP}(\beta 1)$ cysteine substitutions that span the OM (Fig. 4a). A cysteine was also substituted for ${ }^{H i s} \mathrm{BamA}_{\mathrm{V} 784}$ to provide a lumen-facing control.

Consistent with our hypothesis, we observed a significant level of 4-DPS-mediated disulfide-bond formation (typically 10-20\%) between ${ }^{\mathrm{His}} \mathrm{Bam} \mathrm{A}_{\mathrm{F} 785 \mathrm{C}}$ and all of the ${ }^{\mathrm{MBP}-76} \mathrm{EspP}(\beta 1)$ cysteine residues we tested (Fig. 4b, c; Supplementary Fig. 7a, c). There was no clear dependence on the orientation of the ${ }^{\mathrm{MBP}-76} \mathrm{EspP}$ ( $\beta 1)$ cysteine residue. Interestingly, cysteines in the middle of the OM spanning segment $\left({ }^{\mathrm{MBP}-76} \mathrm{EspP}_{\mathrm{A} 1043 \mathrm{C}}\right.$ and $\left.\mathrm{MBP}-{ }^{76} \mathrm{EspP}_{\mathrm{R} 1044 \mathrm{C}}\right)$ formed adducts considerably less efficiently than adjacent cysteines. This observation suggests that MBP ${ }^{-76} \mathrm{EspP}(\beta 1)$ occupies at least two conformational states relative to ${ }^{H i s} B a m A(\beta 15)$. In contrast, none of the ${ }^{M B P}-76 \operatorname{EspP}(\beta 1)$ positions formed adducts with ${ }^{H i s} \mathrm{BamA}_{\mathrm{V} 784 \mathrm{C}}$ (Supplementary Fig. $7 \mathrm{~d}$ ). Thus the outward-facing surface rather than the luminal side of $\operatorname{His} B a m A(\beta 15)$ is in proximity to ${ }^{M B P}-76 \mathrm{EspP}(\beta 1)$. Significant, but less efficient chemically oxidised disulfidebond formation was also observed between ${ }^{\mathrm{MBP}-76} \mathrm{EspP}(\beta 1)$ cysteines and $\mathrm{His}^{\mathrm{BamA}} \mathrm{A}_{\mathrm{I} 806 \mathrm{C}}$ (typically $\sim 5-15 \%$ ) that was likewise orientation-independent (Fig. 4d, e, Supplementary Fig. $7 b, c)$. Because we observed consistently lower interactions between ${ }^{\mathrm{MBP}-76} \mathrm{EspP}(\beta 1) /{ }^{\mathrm{His}} \mathrm{BamA}(\beta 16)$ pairs than between $M B P-76 \operatorname{EspP}(\beta 12) /{ }^{\text {His }} \mathrm{BamA}(\beta 1)$ pairs, we checked if any of the $\mathrm{MBP}-76 \mathrm{EspP}(\beta 1)$ cysteine mutants affected protein biogenesis. We found that the linkers of all but ${ }^{\mathrm{MBP}-76} \mathrm{EspP}_{\mathrm{G} 1040 \mathrm{C}}$ and $\mathrm{MBP}-{ }^{76} \mathrm{EspP}_{\mathrm{W} 1042 \mathrm{C}}$ (which contain substitutions at conserved but uncharacterised autotransporter residues) were protease sensitive and therefore properly exposed on the cell surface (Supplementary Fig. 7e). Given that prolonged periplasmic exposure of the EspP $\beta$-barrel leads to its degradation, however, the stability of the two mutant proteins, in addition to the consistency of the overall disulfide-bonding pattern, indicate that the G1040C and W1042C substitutions do not affect the engagement of MBP-76EspP by BAM. Taken together, these data provide clear evidence for the formation of discrete, 
a
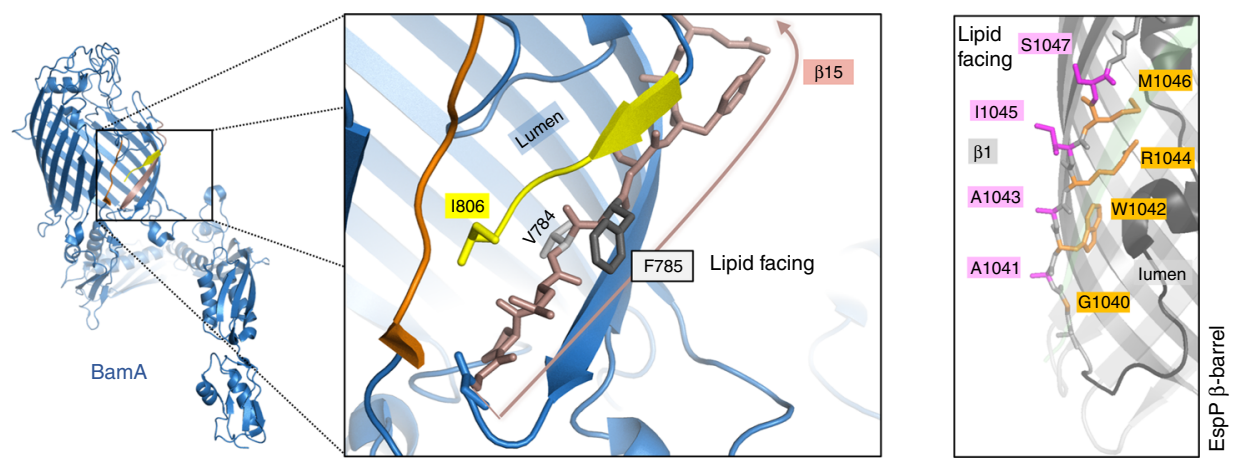

b
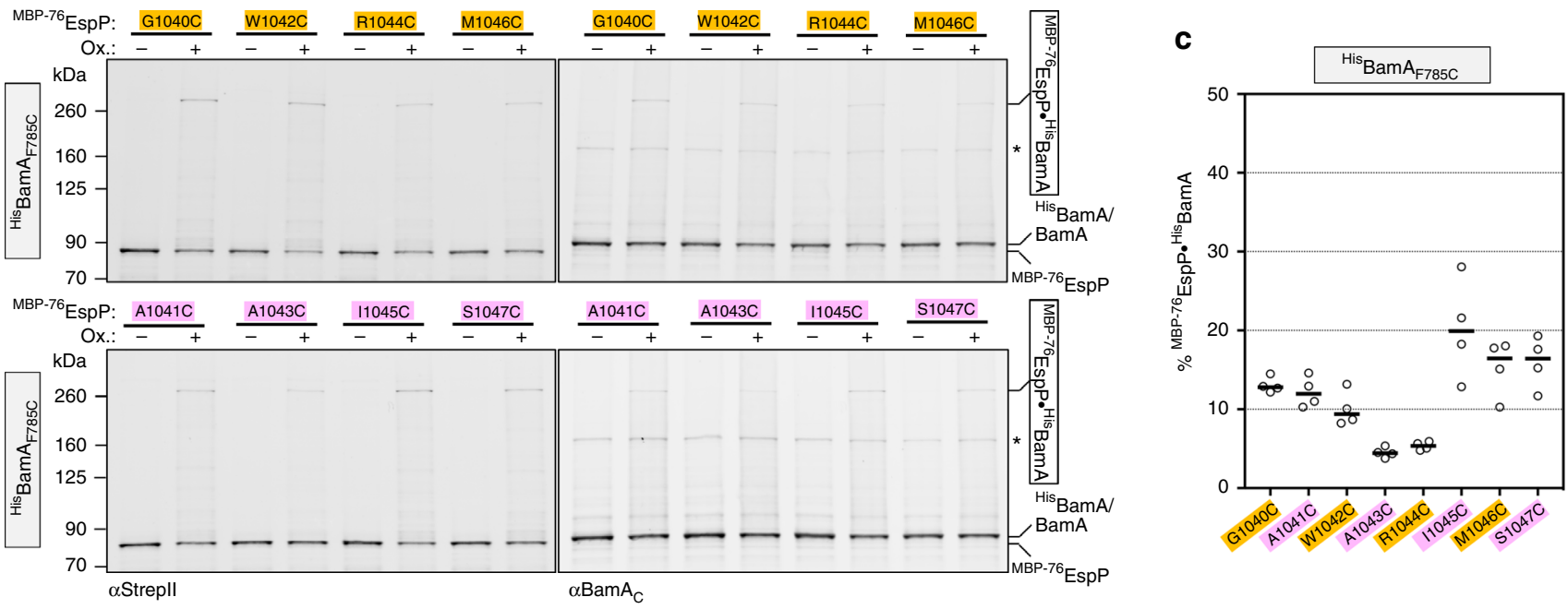

d
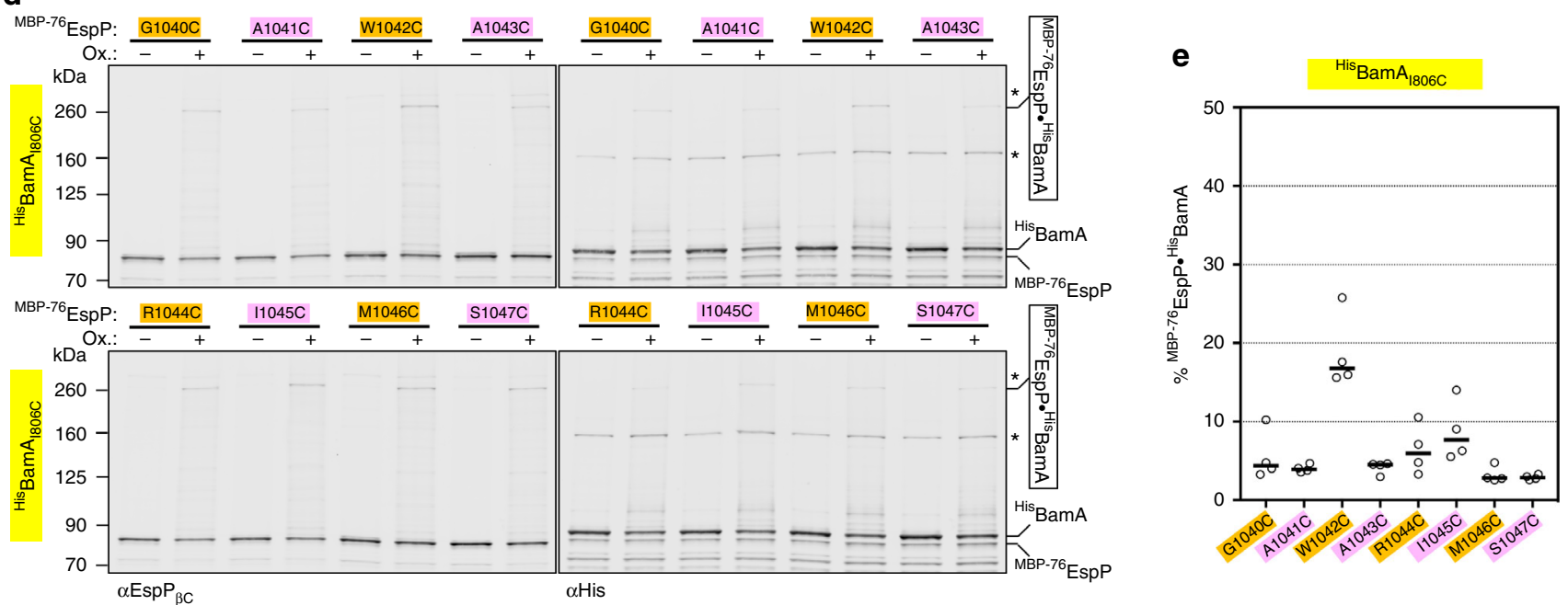

Fig. 4 Bonding of MBP-76 EspP( $\beta 1)$ cysteines with lipid-facing cysteines in $B a m A(\beta 15 / 16)$. a Left, view of outward-facing residues I806 in BamA( $\beta 16$ ) (yellow) and F785 in BamA( $\beta 15)$ (salmon). Right, view of MBP-76 EspP( $\beta 1)$ showing lipid-facing (magenta) and luminal (orange) residues. Residue S1047 is situated at the interface between the outer leaflet of the OM and the extracellular milieu ${ }^{54}$ and is the last membrane embedded residue of $\beta 1$. $\mathbf{b}$, $\mathbf{d}$ BL21 (DE3) that expressed MBP-76EspP with a single cysteine substitution in $\beta 1$ and HisBamABCDE with a HisBam ${ }_{1806 C}(\mathbf{b})$ or HisBamA ${ }_{\text {F785C }}$ (d) substitution were mock-treated $(-)$ or treated with 4-DPS $(+)$. Duplex-immunoblots were then conducted using antibodies/antisera against the $\mathrm{N}$-terminus and $\mathrm{C}$-terminus of $\mathrm{MBP}-76_{\mathrm{EspP}}\left(\alpha \mathrm{Strepll}\right.$ or $\alpha \mathrm{EspP}_{\beta C}$ ) and HisBamA ( $\alpha$ His or $\alpha$ BamA $\mathrm{A}_{C}$ ) to monitor disulfide-bond formation between cysteine pairs in vivo. Non-specific bands are denoted $\left(^{\star}\right)$. Data are representative of at least two independent experiments. $\mathbf{c}$, e Quantitation of disulfide-bond formation between MBP-76EspP $(\beta 1)$ and HisBam $_{1806 \mathrm{C}}(\mathbf{c})$ or HisBamA ${ }_{\mathrm{F} 785 \mathrm{C}}(\mathbf{e})$ cysteine pairs in 4-DPS-treated cells. Experiments were performed as in $\mathbf{b}, \mathbf{d}$ except that only $\alpha$ Strepll was used for probing immunoblots. Bars = median, $N=4$. ANOVA and multiple comparison tests are shown in Supplementary Tables 3 and 4 . Source data are provided as a Source Data file 
a

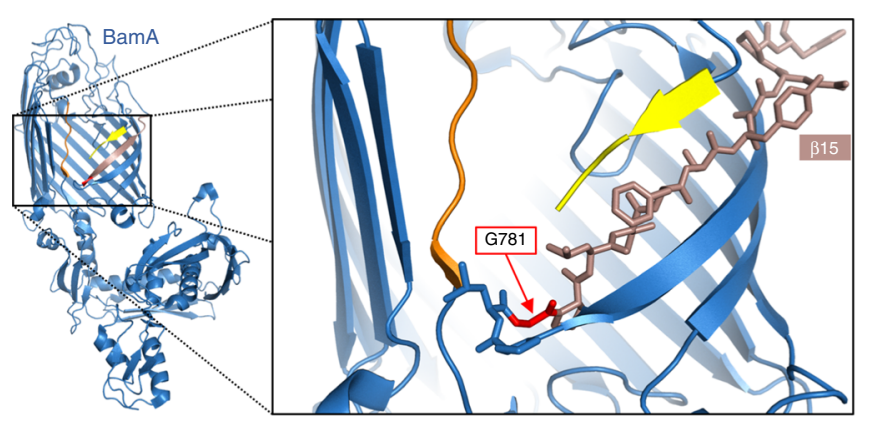

b
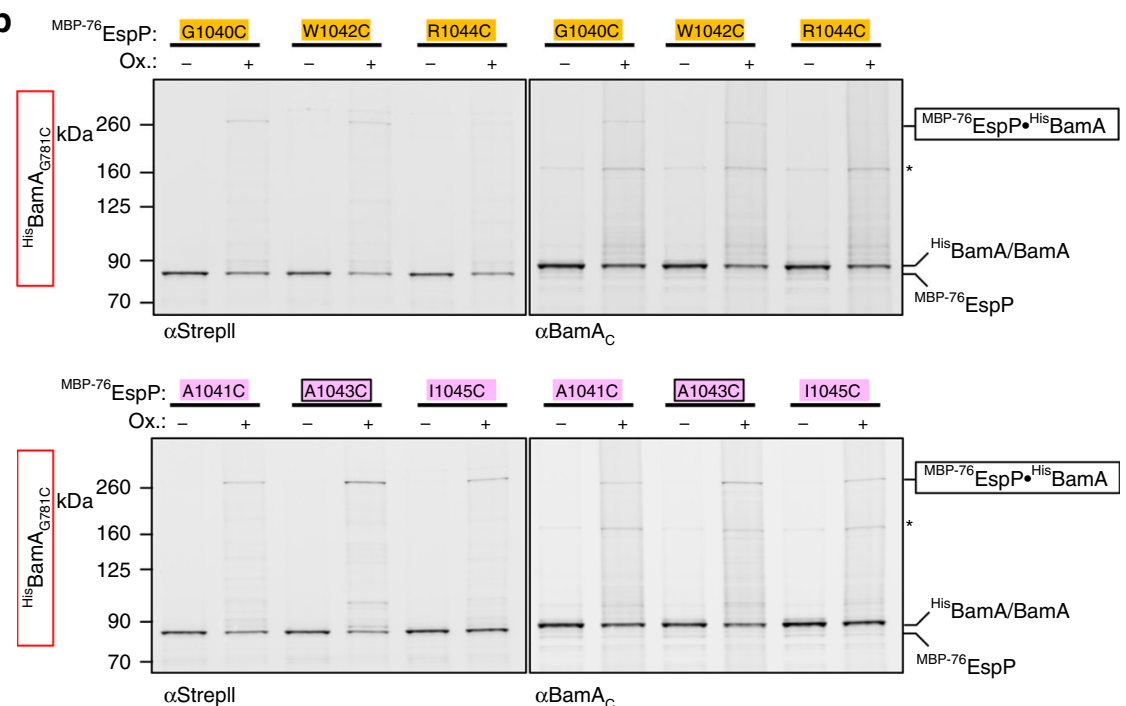

C
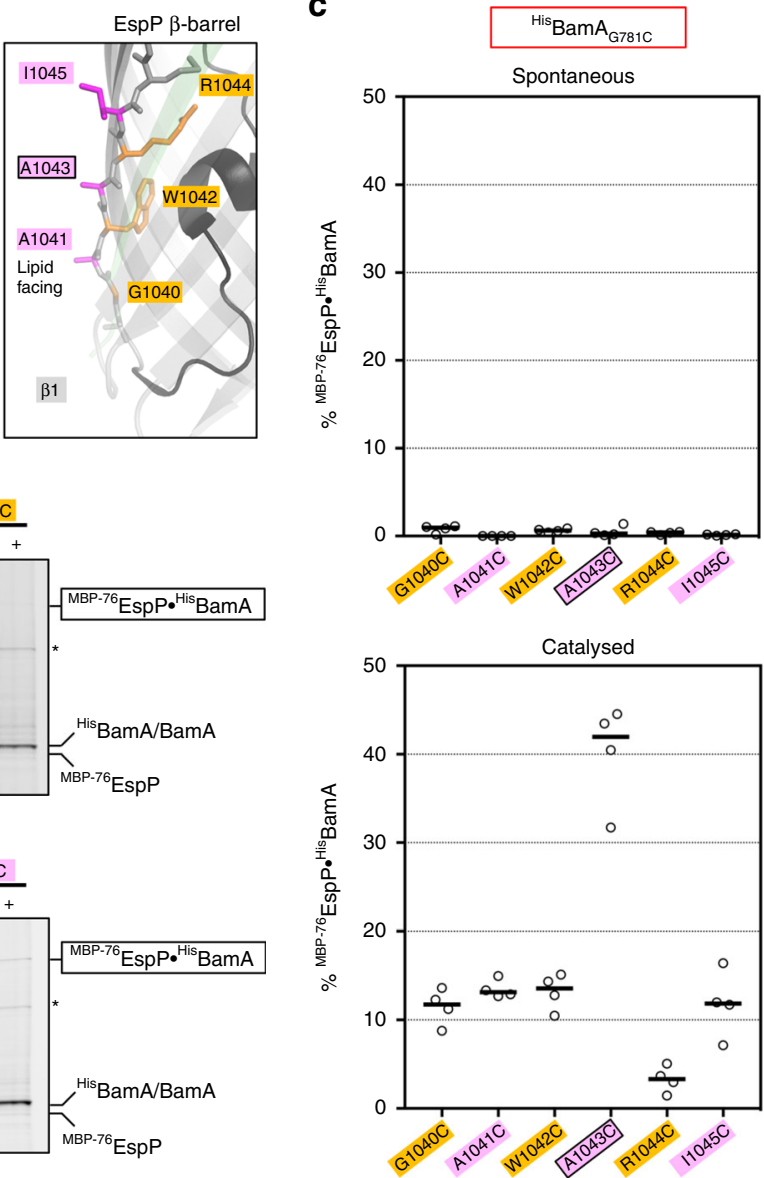

Fig. 5 Strong bond between a mid-strand MBP-76EspP( $\beta 1)$ cysteine and a periplasmic-proximal BamA( $\beta 15)$ cysteine. a Left, view of periplasmic-proximal BamA $\beta$-strand 15 residue $\mathrm{G} 781$ (red) in the lateral opening. Right, view of MBP-76EspP( $\beta 1$ ) showing lipid-facing (magenta) and luminal (orange) residues. b BL21(DE3) that expressed MBP-76 EspP with a single cysteine substitution in $\beta 1$ and His BamABCDE with the His BamA ${ }_{\text {G781C }}$ substitution were mock-treated $(-)$ or treated with 4-DPS (+). Duplex-immunoblots were then conducted using antibodies/antisera against the N-terminus of MBP-76 EspP ( $\alpha$ Strep II) and the $\mathrm{C}$-terminus of His BamA $\left(\alpha B a m A_{C}\right)$ to monitor disulfide-bond formation between cysteine pairs in vivo. Non-specific bands are denoted $\left({ }^{\star}\right)$. Data are representative of at least two independent experiments. c Quantitation of disulfide-bond formation between ${ }^{\mathrm{MBP}}-7{ }^{76} \mathrm{EspP}(\beta 1)$ and ${ }^{H i s} \mathrm{BamA} \mathrm{A}_{\mathrm{G}} \mathrm{B1C}$ cysteine pairs in mock-treated cells ('spontaneous') and 4-DPS-treated cells ('catalysed'). Experiments were performed as in $\mathbf{b}$, except that only $\alpha$ Strepll was used for probing immunoblots. Bars = median, $N=4$. ANOVA and multiple comparison tests are shown in Supplementary Table 5. Source data are provided as a Source Data file

heterogeneous interactions between the outward-facing surface of $\operatorname{BamA}(\beta 15 / \beta 16)$ and ${ }^{\mathrm{MBP}-76} \operatorname{EspP}(\beta 1)$ that were not observed in the analysis of Sam50 function ${ }^{18}$.

Because our analysis of F785 interactions strongly suggested that the outward-facing surface of $\operatorname{BamA}(\beta 15)$ creates a unique interface with $\mathrm{MBP}-76 \mathrm{EspP}(\beta 1)$, we sought to investigate BamA $(\beta 15)$ interactions at positions closer to the periplasmic side of the OM. Perhaps because L783 and P782 are essential for function, we could not introduce cysteine substitutions at these positions. However, we were able to obtain ${ }^{H i s} \mathrm{BamA}_{\mathrm{G} 781 \mathrm{C}}$ and to assess the formation of disulfide-bonds between this residue and the aforementioned ${ }^{\mathrm{MBP}-76} \operatorname{EspP}(\beta 1)$ cysteine substitutions (Fig. 5a). Upon the addition of oxidiser most cysteine-pairs formed a modest level of disulfide-bonded adducts $(\sim 10 \%)$ that was similar to the levels observed in the analysis of His BamA ${ }^{7785 C}$ (Fig. 5b, c, Supplementary Fig. 8). However, the level of disulfide-bond formation between the lipid-facing $\mathrm{MBP}-{ }^{76} \mathrm{EspP}_{\mathrm{A1043C}}$ residue and HisBamA $_{\mathrm{G} 781 \mathrm{C}}$ was considerably higher $(42 \%)$ than that formed between any other $\mathrm{MBP}-76 \mathrm{EspP}(\beta 1) /{ }^{\mathrm{His}} \mathrm{BamA}(\beta 15 / \beta 16)$ cysteine-pair (Fig. $5 \mathrm{~b}, \mathrm{c}$ ). The results suggest that $\mathrm{MBP}-76 \mathrm{Esp}-$ $\mathrm{P}_{\mathrm{A} 1043 \mathrm{C}}$ and ${ }^{\mathrm{His}} \mathrm{BamA}_{\mathrm{G} 781 \mathrm{C}}$ are in close proximity in the most probable of multiple conformational states that can be occupied by $\mathrm{MBP}-76 \mathrm{EspP}(\beta 1)$ and the C-terminus of BamA when the assembly of $\mathrm{MBP}-76 \mathrm{EspP}$ stalls. Importantly, the interaction of $\mathrm{A} 1043 \mathrm{C}$, which is located near the middle of the $\mathrm{OM}$ spanning segment of $\mathrm{MBP}-76 \mathrm{EspP}(\beta 1)$, with ${ }^{\mathrm{His}} \mathrm{BamA}_{\mathrm{G} 781 \mathrm{C}}$, which is located close to the periplasm, strongly suggests that $\mathrm{MBP}-{ }^{76} \operatorname{EspP}(\beta 1)$ is partially in the periplasm and not stably integrated into the OM in this conformational state.

The two MBP-76EspP-BamA interfaces exhibit distinct features. Several observations suggested that when the assembly of $\mathrm{MBP}-{ }^{76} \mathrm{EspP}$ is arrested, it forms two very different barrel-barrel interfaces with $\mathrm{BamA}$. The interaction of $\operatorname{BamA}(\beta 1)$ and the MBP-76EspP $\beta$-signal created a rigid, antiparallel, non-sliding inter-barrel $\beta$-seam. The formation of disulfide-bonds even in the absence of an oxidant attested to the high stability of this interaction. In contrast, ${ }^{\mathrm{MBP}-76} \mathrm{EspP}(\beta 1)$ did not form an analogous interface with $\operatorname{His} \operatorname{Bam} A(\beta 16)$ but rather weaker, more flexible, interactions with outward-facing positions in both ${ }^{H i s} \operatorname{BamA}(\beta 15)$ and ${ }^{\operatorname{His}} \operatorname{BamA}(\beta 16)$ that were dependent 
a

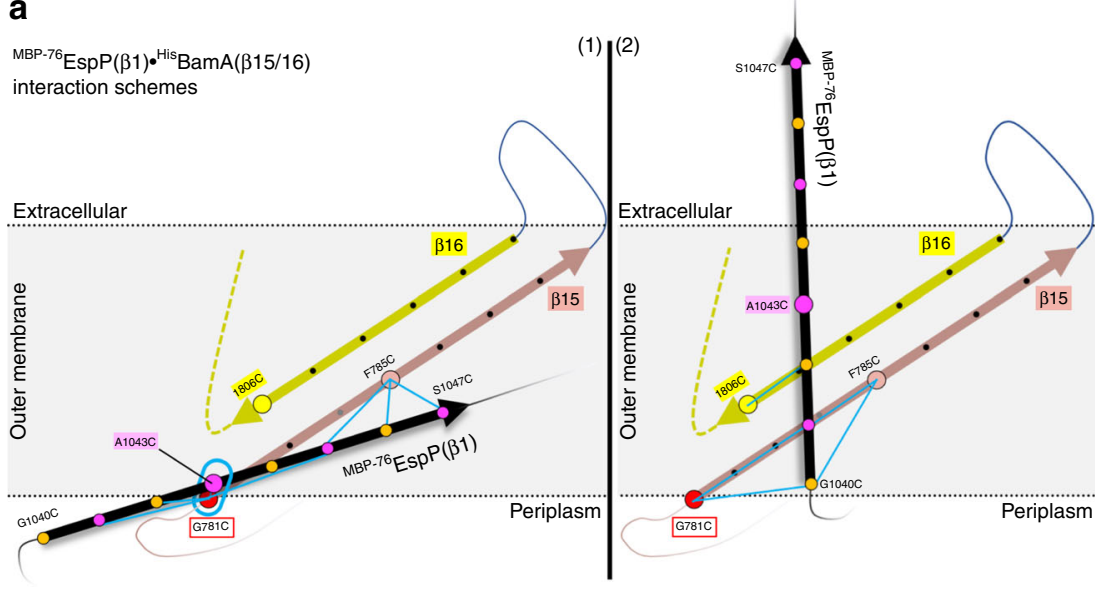

b

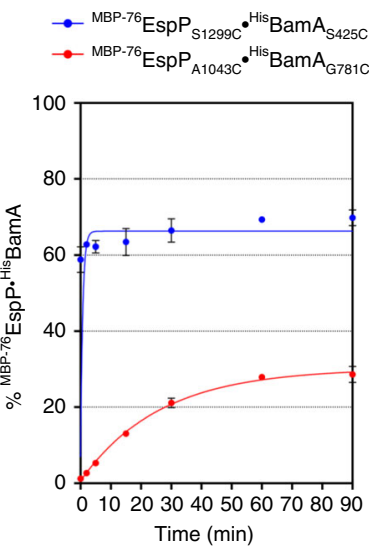

C
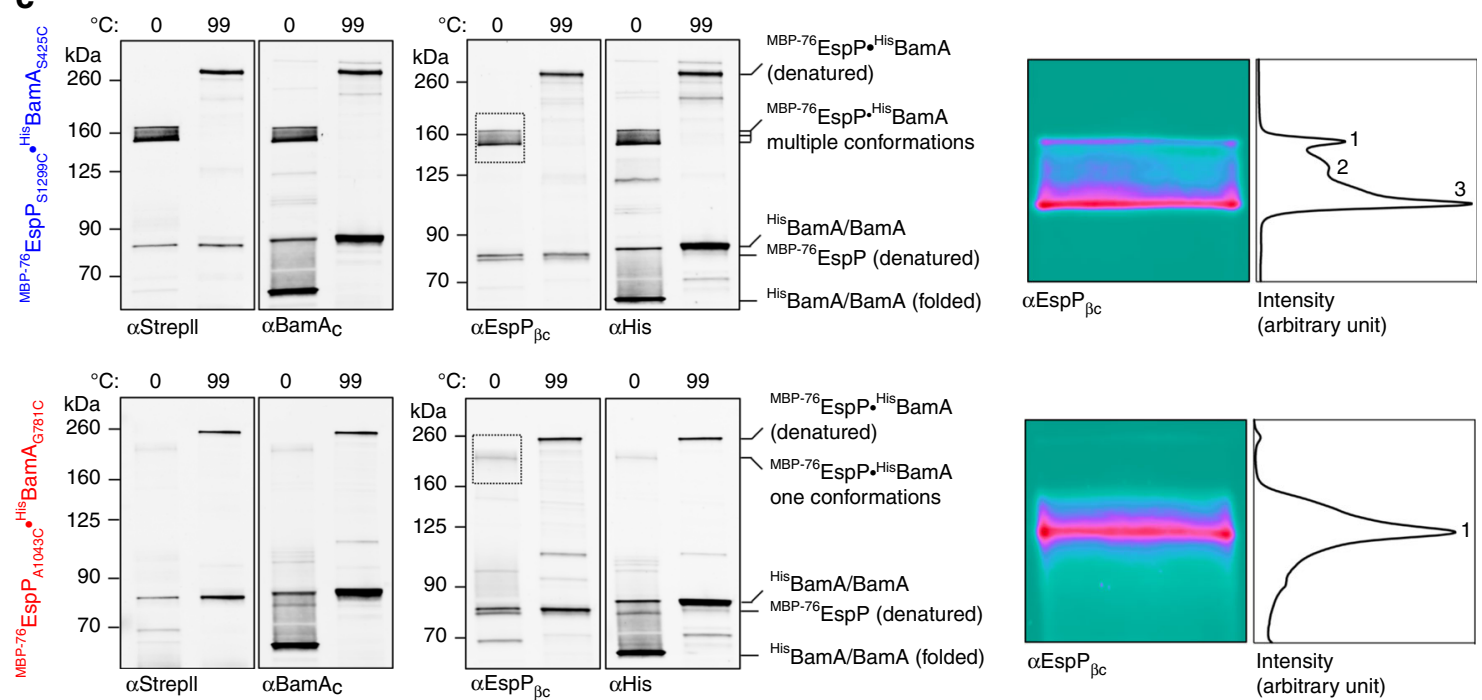

Fig. 6 Distinct properties of the two interfaces formed between MBP-76EspP and BamA. a Models of interactions between MBP-76 EspP( $\beta 1)$ and BamA( $\beta 15 /$ $\beta 16$ ) based on disulfide-bond formation data in Figs. 4 and 5. MBP-76 EspP( $\beta 1$ ) (black), and antiparallel BamA $\beta 15$ (salmon) and $\beta 16$ (yellow), are shown as arrows. The BamA $\beta$-strands are tilted to match their orientation in solved structures. Key residues are represented by coloured circles. Cysteine-pairs that formed disulfide-bonds at a median level of $10-20 \%$ are denoted by blue lines while levels above $40 \%$ are denoted by a blue oval. Although no single model can completely explain the observed disulfide-bond patterns, placement of MBP-76 EspP( $\beta 1)$ in the two orientations that are shown accounts for

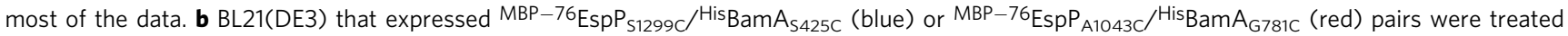
with 4-DPS on ice over a 90 min time course and the kinetics of disulfiide-bond formation was quantitated from immunoblots probed with $\alpha$ Strepll. The

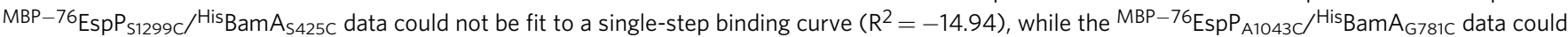

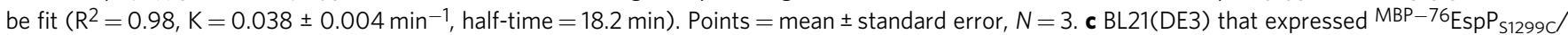
$\mathrm{His}_{\mathrm{BamA}} \mathrm{A}_{\mathrm{S} 25 \mathrm{C}}$ or $\mathrm{MBP}^{-76} \mathrm{EspP}_{\mathrm{A1043C}} /{ }^{\text {His BamA }} \mathrm{A}_{\mathrm{G} 781 \mathrm{C}}$ pairs were treated with 4-DPS. Cell lysates were either unheated $\left(0^{\circ} \mathrm{C}\right)$ or heated $\left(99^{\circ} \mathrm{C}\right)$ and proteins were resolved by cold SDS-PAGE. Duplex-immunoblots were then conducted using $\alpha \mathrm{EspP}_{\beta} / \alpha \mathrm{His}$ or $\alpha$ Strepll/ $\alpha$ BamA $\mathrm{A}_{C}$ antisera/antibodies. Right, image analysis of the boxed regions of the blots was performed using Fiji software and false colouring. Horizontal average intensity plots (arbitrary values) are shown, and distinct peaks are numbered. Representative results from at least two independent experiments are shown. Source data are provided as a Source Data file

on the addition of an oxidant. Because no single placement of $\mathrm{MBP}-76 \mathrm{EspP}(\beta 1)$ relative to ${ }^{\mathrm{His}} \mathrm{BamA}(\beta 15 / 16)$ can account for all of the disulfide-bonds we observed (Fig. 6a), it is likely that multiple conformations that reflect snapshots of different stages of assembly existed.

To further examine the asymmetry between the two barrelbarrel interfaces, we compared the kinetics of disulfide-bond formation between pairs $\mathrm{MBP}^{-76} \mathrm{EspP}_{\mathrm{S} 1299 \mathrm{C}} \mathrm{C}^{\mathrm{His}} \mathrm{BamA}_{\mathrm{S425C}}$ (representing the ${ }^{\mathrm{MBP}-76} \mathrm{EspP}\left(\beta 12^{-\mathrm{His}} \mathrm{BamA}(\beta 1)\right.$ interface) and $\mathrm{MBP}-{ }^{-76} \mathrm{EspP}_{\mathrm{A} 1043 \mathrm{C}} /{ }^{\mathrm{His}} \mathrm{BamA} \mathrm{A}_{\mathrm{G} 781 \mathrm{C}}$ (representing a major conformer of the ${ }^{\mathrm{MBP}-76} \mathrm{EspP}(\beta 1)$ - ${ }^{-H i s} \mathrm{BamA}(\beta 15 / \beta 16)$ interface). A large fraction of the ${ }^{\mathrm{MBP}-76} \mathrm{EspP}_{\mathrm{S1299}} /{ }^{\mathrm{His}} \mathrm{Bam} \mathrm{A}_{\mathrm{S} 425 \mathrm{C}}$ pair formed adducts extremely rapidly and plateaued almost immediately, while cells that expressed ${ }^{\mathrm{MBP}-76} \mathrm{EspP}_{\mathrm{A} 1043 \mathrm{C}}{ }^{\mathrm{His}} \mathrm{BamA}_{\mathrm{G} 781 \mathrm{C}}$ displayed a slow accumulation of adducts during an extended incubation period before plateauing at a much lower level (Fig. 6b, Supplementary Fig. 9a, b). The results show a clear difference in the association stabilities between the two interbarrel interfaces and presumably reflect a difference in local conformational flexibility. The difference in plateaus also provides evidence that when only interactions between ${ }^{\mathrm{His}} \mathrm{Ba}$ $\mathrm{mA}_{\mathrm{G} 781 \mathrm{C}}$ and ${ }^{\mathrm{MBP}-76} \mathrm{EspP}_{\mathrm{A} 1043 \mathrm{C}}$ are monitored, alternate conformations between $\mathrm{MBP}-76 \mathrm{EspP}(\beta 1)$ and the C-terminus of His BamA remain unaccounted for. 
To obtain direct evidence that the two inter-barrel interfaces have distinct conformational properties, we exploited the remarkable ability of folded $\beta$-barrels to resist SDS denaturation in the absence of heat and migrate relatively rapidly on SDS-PAGE. As in the previous experiment, we expressed either ${ }^{\mathrm{MBP}-76} \mathrm{EspP}_{\mathrm{S} 1299 \mathrm{C}} /{ }^{\text {His }} \mathrm{BamA}_{\mathrm{S} 425 \mathrm{C}}$ or ${ }^{\mathrm{MBP}-76} \mathrm{EspP}_{\mathrm{A} 1043 \mathrm{C}} /$ His $\mathrm{BamA}_{\mathrm{G} 781 \mathrm{C}}$ pairs and catalysed disulfide-bond formation with 4-DPS. Cell lysates were then kept on ice or boiled, and proteins were resolved by SDS-PAGE at $0-4{ }^{\circ} \mathrm{C}$. Interestingly, the unheated ${ }^{\mathrm{MBP}-76} \mathrm{EspP}_{\mathrm{S} 1299 \mathrm{C}^{-}}{ }^{-\mathrm{His}} \mathrm{BamA}_{\mathrm{S} 425 \mathrm{C}}$ adduct was detected on duplex immunoblots as at least three discrete fast-migrating species that likely represent distinct conformational states (Fig. 6c, top). Identical results were obtained when the experiment was repeated with another $\mathrm{MBP}-76 \mathrm{EspP}(\beta 12)$ - ${ }^{\mathrm{His}} \mathrm{BamA}(\beta 1)$ pair $\left(\mathrm{MBP}-{ }^{76} \mathrm{EspP}_{\mathrm{N} 1293 \mathrm{C}}\right.$ His $^{\text {His }}{ } \mathrm{AmA}_{\mathrm{G} 431 \mathrm{C}}$ ) (Supplementary Fig. 9b, c).

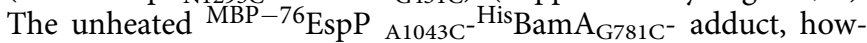
ever, was detected as only a single fast-migrating species (Fig. 6c, bottom). Consistent with the results of previous experiments, these results suggest that when the stable $\mathrm{MBP}-76 \mathrm{EspP}(\beta 12)$ His $\mathrm{BamA}(\beta 1)$ inter-barrel $\beta$-seam is tethered by a disulfide-bond, the opposing $\mathrm{MBP}-76 \mathrm{EspP}(\beta 1)$-BamA C-terminus interface remains free to adopt multiple intermediate conformations. Conversely, when the ${ }^{\mathrm{MBP}-76} \operatorname{EspP}(\beta 1)$ - ${ }^{-H i s} \operatorname{BamA}(\beta 15)$ interface is locked, only one conformation is observed because the opposing inter-barrel $\beta$-seam exists as a single stable state.

\section{Discussion}

In this study we describe a structure-guided interaction map of BamA bound to an OMP assembly intermediate in vivo with disulfide-bond resolution. To perform our analysis, we first engineered a fusion protein in which an MBP moiety arrests the translocation of an autotransporter passenger domain and thereby traps the $\beta$-barrel in a stable, incompletely assembled state. After validating $\mathrm{MBP}-76 \mathrm{EspP}$ as an assembly intermediate by showing that the arrest of assembly is reversible, we pinpointed positions in BamA and ${ }^{\mathrm{MBP}-76} \mathrm{EspP} \beta$-barrels that are in close proximity by monitoring intermolecular disulfide-bond formation after the addition of an oxidant. We found that the two proteins interact via two distinct interfaces that create an asymmetric hybrid-barrel. On one side, the EspP $\beta$-signal formed a rigid antiparallel inter-barrel $\beta$-seam with $\operatorname{BamA}(\beta 1)$. This observation rules out an 'assisted' model in which BamA catalyses assembly simply by perturbing the lipid bilayer. Unexpectedly, no analogous interface between $\operatorname{BamA}(\beta 16)$ and ${ }^{\mathrm{MBP}-76} \mathrm{EspP}(\beta 1)$ was observed. Instead, we identified diverse, relatively weak interactions between the outward-facing surface of $\operatorname{BamA}(\beta 15 /$ $\beta 16)$ and ${ }^{\mathrm{MBP}-76} \operatorname{EspP}(\beta 1)$ that indicated the presence of multiple conformations. Remarkably, in the most common conformer the middle of the $\mathrm{MBP}-76 \mathrm{EspP}(\beta 1)$ transmembrane segment was positioned near the most periplasmic-proximal position of BamA $(\beta 15)$. In this state, part of the EspP $\beta$-barrel presumably remained in the periplasm. Finally, an analysis of disulfide-bond formation kinetics and mobility states on SDS-PAGE provided direct evidence that one inter-barrel interface is stable, while the other is conformationally heterogeneous.

Although hybrid-barrel formation and an analogous interaction between Sam50( $\beta 1)$ and the $\beta$-signal of client proteins was also recently reported in an examination of interactions between Sam50 and C-terminal fragments of mitochondrial $\beta$-barrels ${ }^{18}$, our results differ from those of the previous study in several critical respects. First, the previous study reported a potentially strong interface between $\operatorname{Sam} 50(\beta 16)$ and the N-terminal $\beta$ strand of the client that we did not observe in our analysis of the interaction of BamA and MBP-76EspP. Second, a predominant conformational state in which the first $\beta$-strand of an incoming $\beta$-barrel does not appear to be fully integrated into the $\mathrm{OM}$ $\left({ }^{\mathrm{MBP}}-76 \mathrm{EspP}_{\mathrm{A} 1043 \mathrm{C}^{-}}{ }^{\text {His }} \mathrm{BamA}_{\mathrm{G} 781 \mathrm{C}}\right)$ was not identified in the Sam50 study. Most significantly, while we observed disulfidebond formation between $\mathrm{MBP}-76 \mathrm{EspP}(\beta 1)$ and the outwardfacing surface of $\operatorname{BamA}(\beta 15 / 16)$, chemical crosslinking of $\mathrm{N}$ terminal residues of mitochondrial $\beta$-barrel fragments to luminal residues of $\operatorname{Sam} 50(\beta 15)$ and an internal loop of Sam50 was observed in the previous study. Those results provided evidence for a model involving initial threading of unfolded $\beta$-barrels into the Sam50 lumen, progressive folding between the two sides of an open Sam50 lateral-gate, and release of the full-length protein into the lipid bilayer ${ }^{18}$. Similar models for OMP assembly that posit the stepwise formation of a hybrid-barrel within the plane of the OM have been proposed based on the crystal structures of $\mathrm{BamA}^{24}$ and $\mathrm{TamA}^{48}$, another member of the Omp85 family.

There are several possible explanations for the discrepancies between our study and the Sam50 study. It is conceivable that the use of $\beta$-barrel fragments in the Sam50 study captured an earlier stage of the assembly process than we observed through the use of a complete $\beta$-barrel. Alternatively, N-terminally truncated mitochondrial $\beta$-barrels might interact differently with Sam50 than native clients in vivo. An especially intriguing possibility, particularly in light of the functional diversity of members of the Omp85 superfamily ${ }^{5,17}$, is that the catalytic mechanisms of BamA and Sam50 have diverged. Indeed, $S$. cerevisiae Sam50 and E. coli BamA share only $21 \%$ sequence similarity, have a different number of POTRA domains, function in dissimilar membrane environments, and form complexes with unrelated accessory proteins that have opposite membrane topologies ${ }^{11}$. Furthermore, Sam50 and BamA may catalyse the assembly of client proteins that have distinct folding requirements. For instance, bacterial OMPs are profoundly structurally diverse and contain an even number of $\beta$ strands that necessitates the formation of an antiparallel $\beta$ seam, while mitochondrial $\beta$-barrels (besides Sam50) are all members of a single family of 19-stranded proteins that have a parallel $\beta$-seam ${ }^{11,49}$. Importantly, if the assembly mechanisms used by Sam 50 and BamA have diverged, it might be possible to design antibiotics that target $\mathrm{BamA}^{50}$ but that do not cause mitochondrial toxicity.

Regardless of the reason that disparate results were obtained in the two studies, we propose that BamA functions by actively integrating client proteins into the OM from the periplasm via a 'swing' mechanism rather than progressively threading them through a lateral gate. In this model, the $\beta$-signal of a partially folded client protein forms a transiently stable interaction with $\operatorname{BamA}(\beta 1)$ that creates an inter-barrel $\beta$-seam (Fig. 7, stage $i$; Supplementary Video 1). The inter-barrel $\beta$-seam maintains the association between the two barrels while BamA acts as a molecular hinge that allows the $\mathrm{N}$-terminus of the client $\beta$-barrel to move along the outward-facing surface of its C-terminal strands and integrate into the OM through a swinging action (Fig. 7, stage ii). Although we cannot order a series of intermediate conformations from our steady-state data, it seems likely that the diverse interactions that we observed between ${ }^{\mathrm{MBP}-76} \mathrm{EspP}(\beta 1)$ and lipid-exposed residues of $\operatorname{BamA}(\beta 15 / \beta 16)$ represent assembly snapshots of the partially folded OMP moving along the outwardfacing surface of BamA into the plane of the OM. The strong ${ }_{\mathrm{MBP}}{ }^{-76} \mathrm{EspP}_{\mathrm{A} 1043 \mathrm{C}^{-}}{ }^{\mathrm{His}} \mathrm{BamA}_{\mathrm{G} 781 \mathrm{C}}$ interaction (which in itself provides clear evidence that the $\beta$-strands do not simply partition into the lipid bilayer through a lateral-gate) presumably corresponds to an early state in which much of the client is still positioned in the periplasm. In a final step, the client is released from BamA into the lipid bilayer as a fully assembled $\beta$-barrel (Fig. 7, stage iii). We speculate that the asymmetry helps complete assembly by promoting the energetically favourable closure of the 


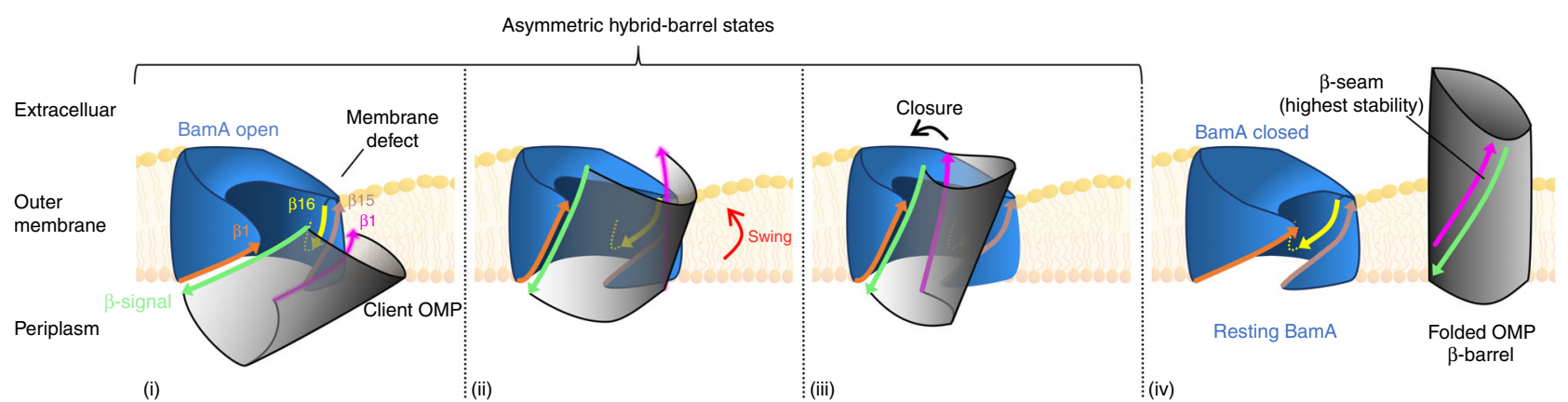

Fig. 7 Model of bacterial outer membrane protein assembly. Red arrows indicate possible conformational changes. After an OMP (grey) is targeted to the $\mathrm{OM}$, it interacts with the BamA $\beta$-barrel (blue). Initially the C-terminal $\beta$-strand of the OMP ( $\beta$-signal, green) forms a $\beta$-seam with BamA $\beta 1$ (orange) to create an asymmetric hybrid barrel (i). It is not yet clear if the OMP begins to fold before or after the formation of this interface. Subsequently the first $\beta$ strand of the OMP (magenta) forms a low stability interface with the outward-facing surface of BamA $\beta 15 / 16$ (salmon/yellow) (ii). A large-scale movement of the OMP into the membrane ('swing') is aided by the rotation of BamA $\beta 1-\beta 8$, the perturbation of the lipid bilayer by the wedge-shape of the BamA $\beta$-barrel, and the dynamicity of $\beta 16$. The asymmetry between the two interfaces favours the closure of the client $\beta$-barrel (iii) and its release into the lipid bilayer in a native conformation (iv). Our results suggest that a loop of the MBP-76EspP passenger domain is exposed on the cell surface prior to most of the swinging action

client $\beta$-barrel and restoration of the BamA ground state through a $\beta$-signal exchange (Fig. 7, stage iv).

The results of numerous previous studies on OMP biogenesis are consistent with a 'swing' model for BamA function. First and foremost, there is now considerable evidence from in vivo studies on EspP, trimeric adhesins and the LPS transporter complex LptDE that OMPs begin to fold prior to their integration into the $\mathrm{OM}^{27-32}$ and are therefore unlikely to be inserted by progressive threading. Many of the results suggest that folding begins in the periplasm or is promoted by interactions with the BAM lipoproteins or the BamA POTRA domains that precede interactions with the BamA $\beta$-barrel. As suggested in a recently proposed 'elongation' model, however, it is conceivable that the initial association of the $\beta$-signal with $\operatorname{BamA}(\beta 1)$ nucleates subsequent $\mathrm{C}$ - to N-terminal folding on the periplasmic side of the $\mathrm{OM}^{10}$. Second, evidence that the effect of lipid-facing arginine residues on OMP biogenesis is highly dependent on membrane depth is consistent with the notion that charged groups hinder productive passage through a hydrophobic environment ${ }^{51}$. Structural studies also support a 'swing' model. Solved structures of BAM show that the transition between the 'closed' and 'open' states of the BamA $\beta$-barrel involves a remarkable scissor-like $45^{\circ}-65^{\circ}$ rotation of $\operatorname{BamA}(\beta 1-\beta 8)^{19,20}$ that could represent the hinge mechanism for a major swinging action of client OMPs. There is also substantial evidence that the wedge-shaped aromatic-girdle of BamA and the highly dynamic properties of $\mathrm{BamA}(\beta 16)$ promote membrane thinning and disorder near the lateral opening $24-26,47$. This membrane perturbation would potentially drive the swinging movement of partially folded $\beta$-barrels into the OM by lowering the energy barrier for integration and by promoting hydrophobic interactions between their outer surface and membrane lipids. Finally, our model fits well with recent bioinformatic evidence that the C-terminal half of OMPs is especially well conserved ${ }^{52}$. We speculate that the need to form an asymmetric hybrid-barrel during assembly constrains the C-terminal sequences of OMPs but provides the freedom for evolution through $\mathrm{N}$-terminal modifications ${ }^{52}$.

\footnotetext{
Methods

Plasmid construction. The plasmids that were used in our experiments are listed in Supplementary Table 6. Oligonucleotide primers and dsDNA fragments that were used in plasmid construction are listed in Supplementary Table 7. To construct pMTD321, a plasmid that encodes an MBP fusion to the EspP $\beta$-barrel with a 115aa-linker, a DNA fragment encoding malE was PCR amplified using primers Mal.Eag $(+) /$ Mal.Eag $(-)$ and pMAL-p2x as a template, digested with EagI, and
}

ligated into the EagI site of $\mathrm{pJH} 64^{53}$ to create $\mathrm{pJH} 64::$ malE. The open reading frame of the fusion protein was then PCR amplified using primers mtd1/pTRC $399 \mathrm{R}$ and pJH64::malE as a template, digested with NdeI and HindIII, and sub-cloned into similarly digested $\mathrm{pWK} 1^{38}$, a derivative of the rhamnose-inducible plasmid pSCrhaB2 ${ }^{43}$. Finally, the resulting plasmid was PCR amplified with primers mtd96/ mtd97 and mixed with dsDNA fragment mtd95 to attach a TwinStrepII-tag to the fusion protein via Gibson assembly. To construct plasmids that encode MBP fusions to the EspP $\beta$-barrel with 97, 76, or 59aa-linkers (pMTD501, pMTD502 and pMTD610, respectively), pMTD321 was PCR amplified using primers mtd145/ mtd146, mtd145/mtd147, or mtd145/164, respectively, digested with BamHI, and re-circularised. To make pMTD521 and pMTD607 (pRha ${ }^{\mathrm{MBP}-76} \mathrm{EspP}$ ), which encode an MBP fusion to the EspP $\beta$-barrel with a 76aa-linker and a TEV cleavage site between EspP residues 974/975 or 984/985, respectively, pMTD502 was PCR amplified using primers mtd135/136 or mtd160/161 and assembled with mtd137 or mtd159 dsDNA fragments (encoding TEV cleavage sites). Plasmid pMTD826, which encodes ${ }^{76} \mathrm{EspP}$, was generated by first introducing a second BamHI site into pMTD607 using primers mtd186/187 together with the QuikChange II SiteDirected Mutagenesis Kit (Agilent). The resulting plasmid (pMTD798) was then digested with BamHI and re-circularised. To construct pMTD372 (pTrc99a: His 8 bamABCDE), $\mathrm{pJH} 114^{34}$ was PCR amplified using primers mtd102/mtd103 and assembled with dsDNA fragment mtd101 (encoding a His8 tag). The resulting plasmid (pMTD366) was subsequently mutagenised using primers mtd104/mtd105 to re-introduce the native bamE stop codon. Cysteine substitution mutations were introduced into pMTD372 and pMTD607 by site-directed mutagenesis as described above.

Culture conditions. E. coli B strain BL21(DE3) (Invitrogen catalog number C600003) was used in all experiments. Cells transformed with appropriate plasmids were grown from a single colony in Lysogeny broth (LB) (Miller) at $25^{\circ} \mathrm{C}$ with orbital shaking at $250 \mathrm{rpm}$ overnight. Overnight cultures were pelleted $(3000 \times g, 5 \mathrm{~min}$, $4^{\circ} \mathrm{C}$ ), washed, and resuspended with one culture volume of LB before seeding subcultures at $\mathrm{OD}_{600}=0.05$ in Erlenmeyer flasks with loose lids. Subcultures were grown for $4 \mathrm{~h}\left(25^{\circ} \mathrm{C}, 250 \mathrm{rpm}\right)$ to $\mathrm{OD}_{600} \sim 0.4-0.6$, induced with $0.4 \mathrm{mM}$ IPTG for $1 \mathrm{~h}$, then induced for $45 \mathrm{~min}$ with $0.2 \% \mathrm{~L}$-rhamnose. Growth media were supplemented with ampicillin $\left(100 \mu \mathrm{g} \mathrm{mL}^{-1}\right)$ or trimethoprim $\left(50 \mu \mathrm{g} \mathrm{mL}^{-1}\right)$ as necessary.

Western immunoblotting, imaging and quantitation. Proteins were separated by SDS-PAGE on $8-16 \%$ Tris-glycine gels (Invitrogen) and transferred to nitrocellulose membranes using an iBlotII (Life Technologies). Immunoblot buffer [Odyssey Blocking Buffer (Licor) diluted by half with PBS and supplemented with $0.01 \%$ Tween 20 ] was used for all blocking and antibody/antisera incubations, PBS $+0.01 \%$ Tween 20 (PBST) for initial washes, and PBS for final washes. Monoclonal mouse anti-StrepII and anti-His antibodies were obtained from Qiagen (catalog number 34850) and Genscript (catalog number A00186), respectively. Polyclonal rabbit antisera raised against EspP $\beta$-barrel and BamA C-terminal peptides have been described previously ${ }^{30}$. A polyclonal rabbit antiserum was also generated against a peptide derived from the $\mathrm{N}$ terminus of the EspP $\beta$-barrel domain ( $\mathrm{NH}_{2}$-NLNKRMGDLRDINGEAGAWARC-COOH). Secondary antibodies [goat anti-mouse 800CW (IRDye catalog number 926-32210) and goat anti-rabbit 680LT (IRDye catalog number 926-68021)] were obtained from Licor. Membranes for quantitation were blocked for $1 \mathrm{~h}$, incubated with anti-StrepII (1:5000 dilution) for $1 \mathrm{~h}$, washed $(3 \times 5 \mathrm{~min}$ with PBST), incubated with goat anti-mouse $800 \mathrm{CW}$ (1:5000 dilution) for $1 \mathrm{~h}$, washed $(3 \times 5 \mathrm{~min}$ with PBST, $2 \times 5 \mathrm{~min}$ PBS $)$, and air 
dried. The membranes were then scanned using an Amersham Typhoon 5 imager (GE Healthcare) with a $785 \mathrm{~nm}$ laser, IRlong $825 \mathrm{BP} 30$ filter, and PMT set at $700 \mathrm{~V}$. Pixel intensities of detected proteins were measured using Fiji software (v2.0.0-rc$68 / 1.52 \mathrm{~g}$ ). Within-lane values were used to calculate percent disulfide-bond formation [(MBP-76 EspP_His BamA/(free MBP-76 EspP + MBP-76EspP-His BamA) $\times$ 100]. Otherwise, membranes for single- or duplex-immunoblots were typically incubated overnight with primary antibodies/antisera and for $2 \mathrm{~h}$ with secondary antibodies. Dried membranes were imaged with an Odyssey infrared imager (Licor, model 9120) or a Typhoon 5 imager using maximum quality and resolution settings. Uncropped images of all blots are included in the Source Data file.

Cell surface protease digestions and arrest-release assembly. To monitor the surface exposure of the ${ }^{\mathrm{MBP}-76} \mathrm{EspP}$ linker or the protease sensitivity of BamA loop $6,1 \mathrm{~mL}$ samples of induced bacterial subcultures were aliquoted into $1.5 \mathrm{~mL}$ tubes on ice. Cells were pelleted $\left(10,000 \times g, 2 \mathrm{~min}, 4^{\circ} \mathrm{C}\right)$, resuspended in $0.5 \mathrm{~mL}$ PBS, and incubated on ice for $20 \mathrm{~min}$ (unless otherwise indicated) with $200 \mu \mathrm{g} \mathrm{mL}-1$ Proteinase K (PK) or equivalent volume of PK buffer $\left(5 \mathrm{mM} \mathrm{CaCl}_{2}, 50 \mathrm{mM}\right.$ TrisHCL $\mathrm{pH}$ 8) for the mock-treated control. For TEV digestions, cells were resuspended in M9 medium with $2 \mathrm{mM}$ DTT and incubated at $25^{\circ} \mathrm{C}$ for $2 \mathrm{~h}$ with $50 \mu \mathrm{g}$ $\mathrm{mL}^{-1}$ TEV protease (hyperactive S219V mutant, obtained from Dr. Susan Buchanan). To observe the completion of $\beta$-barrel assembly following the release of MBP, cells were resuspended in PBS at $25^{\circ} \mathrm{C}$ and incubated with $200 \mu \mathrm{g} \mathrm{mL} \mathrm{L}^{-1} \mathrm{PK}$ $\left[25^{\circ} \mathrm{C}, 350 \mathrm{rpm}\right.$, in a Thermomixer (Eppendorf)] for 0.5, 2, 10 and $30 \mathrm{~min}$. Cells were then pelleted $\left(10,000 \times g, 20 \mathrm{~s}, 4^{\circ} \mathrm{C}\right)$, resuspended in $0.5 \mathrm{~mL}$ PBS, and incubated with $4 \mathrm{mM}$ PMSF and $10 \%$ (v/v) TCA on ice for $10 \mathrm{~min}$ to inhibit PK and precipitate proteins. TCA precipitates were pelleted $\left(20,817 \times g, 10 \mathrm{~min}, 4^{\circ} \mathrm{C}\right)$, washed with $0.6 \mathrm{~mL}$ acetone, pelleted again, and air dried at $37^{\circ} \mathrm{C}$ for $15 \mathrm{~min}$. Dried precipitates were resuspended with 2x SDS protein gel loading solution (Quality Biological) in a volume normalised to the final $\mathrm{OD}_{600}$ reading (volume, $\mu \mathrm{L}=$ $\left.\mathrm{OD}_{600} \times 200\right)$ and heated at $99^{\circ} \mathrm{C}$ for $15 \mathrm{~min}$.

Disulfide-bond formation assay. To observe site-specific intermolecular proteinprotein interactions, $1 \mathrm{~mL}$ samples of induced subculture cells were aliquoted into $1.5 \mathrm{~mL}$ tubes on ice, pelleted $\left(10,000 \times g, 2 \mathrm{~min}, 4^{\circ} \mathrm{C}\right)$, and resuspended in $1 \mathrm{~mL}$ PBS. Cells were incubated with the thiol-specific oxidiser 4,4'-dipyridyl disulfide (4-DPS) at a final concentration of $0.2 \mathrm{mM}$ (or an equivalent volume of ethanol for mock-treated controls) and incubated on ice for $30 \mathrm{~min}$. Cells were then pelleted $\left(10,000 \times g, 2 \mathrm{~min}, 4^{\circ} \mathrm{C}\right)$, resuspended in $0.5 \mathrm{~mL} \mathrm{PBS}$, and mixed with TCA to precipitate proteins as described above. To monitor the kinetics of intermolecular disulfide-bond formation, $5 \mathrm{~mL}$ samples of induced subculture were aliquoted into $50 \mathrm{~mL}$ tubes on ice, pelleted $\left(3000 \times g, 4 \mathrm{~min}, 4^{\circ} \mathrm{C}\right)$, and washed with $10 \mathrm{~mL}$ PBS. Cells were then resuspended in $5 \mathrm{~mL}$ PBS and incubated with $0.2 \mathrm{mM} 4$-DPS or ethanol (mock-treated) for 0, 2, 5, 15, 30, 60 and $90 \mathrm{~min}$. At each time point $0.4 \mathrm{~mL}$ aliquots were dispensed into $1.5 \mathrm{ml}$ tubes pre-loaded with PMSF and TCA for instant protein precipitation. TCA precipitates were washed and mixed with $2 \mathrm{x}$ SDS protein gel loading solution as described above. Control samples were reduced with $150 \mathrm{mM}$ dithiothreitol (DTT) during heating.

Release of assembly arrest and disulfide-bond reduction. To restart $\beta$-barre assembly following the release of MBP and the reduction of ${ }^{\mathrm{MBP}}-7{ }^{2} \mathrm{EspP}-{ }^{-H i s} \mathrm{BamA}$ inter-barrel disulfide-bonds, $20 \mathrm{~mL}$ samples of induced subculture were aliquoted into $50 \mathrm{~mL}$ tubes on ice and pelleted $\left(3000 \times g, 5 \mathrm{~min}, 4^{\circ} \mathrm{C}\right)$. Cells were washed with $40 \mathrm{~mL}$ PBS, pelleted $\left(4000 \times \mathrm{g}, 6 \mathrm{~min}, 4^{\circ} \mathrm{C}\right)$, and resuspended in $10 \mathrm{~mL}$ PBS. Cell aliquots $(0.5 \mathrm{~mL})$ were placed into $1.5 \mathrm{~mL}$ tubes, incubated with $0.2 \mathrm{mM}$ 4-DPS for $30 \mathrm{~min}$ on ice, pelleted $\left(10,000 \times \mathrm{g}, 2 \mathrm{~min}, 4^{\circ} \mathrm{C}\right)$, and resuspended in $0.5 \mathrm{~mL}$ PBS. Cells were then incubated with either $200 \mu \mathrm{g} \mathrm{mL}^{-1}$ PK or PK buffer (mock digest) for $30 \mathrm{~min}$ on ice, washed with $1 \mathrm{~mL}$ PBS, and resuspended in $0.5 \mathrm{~mL}$ PBS (containing $1 \mathrm{mM}$ PMSF) pre-warmed to $25^{\circ} \mathrm{C}$. Cells were then incubated in a Thermomixer $\left(25^{\circ} \mathrm{C}, 350 \mathrm{rpm}\right)$ either in $50 \mathrm{mM}$ HEPES pH 7 containing $150 \mathrm{mM}$ DTT or without DTT (mock-treated) for $0.5,2,5$ and 15 min. All samples were TCA precipitated on ice and prepared for SDS-PAGE as above.

Gel mobility-shift assay. To observe hybrid-barrel conformational states, cysteine pairs were oxidised as described above. Cells were then resuspended in BugBuster Master Mix (EMD Millipore) containing EDTA-free SigmaFast protease inhibitor (Sigma-Aldrich) (volume, $\mu \mathrm{L}=\mathrm{OD}_{600} \times 100$ ) and lysed on ice for $3 \mathrm{~min}$. Aliquots $(30 \mu \mathrm{L})$ of lysates were mixed with $10 \mu \mathrm{L} 2 \mathrm{x}$ SDS protein gel loading solution to bring the final SDS concentration to $1 \%$. Samples were either maintained on ice or heated to $99^{\circ} \mathrm{C}$ for $10 \mathrm{~min}$. Proteins were then resolved by 'cold' SDS-PAGE (i.e., by packing gel tanks in ice and running the gels in a $4^{\circ} \mathrm{C}$ room) and transferred to nitrocellulose for immunoblotting as described above.

\section{Data availability}

Data supporting the findings of this paper are available from the corresponding author upon reasonable request. A reporting summary for this Article is available as a Supplementary Information file. The source data underlying Figs. $1 d-e, 2 b-e, 3 b-c, 4 b-e$, $5 \mathrm{~b}-\mathrm{c}, 6 \mathrm{~b}-\mathrm{c}$ and Supplementary Figs. 1a-c, 2a-c, 3a-d, 4a-c, 5, 6a-e, 7a-e, 8, 9a-d are provided as a Source Data file.
Received: 21 March 2019 Accepted: 28 June 2019

Published online: 26 July 2019

\section{References}

1. Rojas, E. R. et al. The outer membrane is an essential load-bearing element in Gram-negative bacteria. Nature 559, 617-621 (2018).

2. Jaroslawski, S., Duquesne, K., Sturgis, J. N. \& Scheuring, S. High-resolution architecture of the outer membrane of the Gram-negative bacteria Roseobacter denitrificans. Mol. Microbiol 74, 1211-1222 (2009).

3. Klebba, P. E. \& Newton, S. M. C. Mechanisms of solute transport through outer membrane porins: burning down the house. Curr. Opin. Microbiol 1, 238-247 (1998).

4. Lauber, F., Deme, J. C., Lea, S. M. \& Berks, B. C. Type 9 secretion system structures reveal a new protein transport mechanism. Nature 564, 77-82 (2018).

5. Stubenrauch, C. et al. Effective assembly of fimbriae in Escherichia coli depends on the translocation assembly module nanomachine. Nat. Microbiol 1, 16064 (2016).

6. Heras, B. et al. The antigen 43 structure reveals a molecular Velcro-like mechanism of autotransporter-mediated bacterial clumping. Proc. Natl Acad. Sci. USA 111, 457-462 (2014).

7. Konovalova, A., Kahne, D. E. \& Silhavy, T. J. Outer membrane biogenesis Annu Rev. Microbiol 71, 539-556 (2017).

8. Schulz, G. E. beta-Barrel membrane proteins. Curr. Opin. Struct. Biol. 10, 443-447 (2000)

9. Struyve, M., Moons, M. \& Tommassen, J. Carboxy-terminal phenylalanine is essential for the correct assembly of a bacterial outer membrane protein. J. Mol. Biol. 218, 141-148 (1991).

10. Schiffrin, B., Brockwell, D. J. \& Radford, S. E. Outer membrane protein folding from an energy landscape perspective. BMC Biol. 15, 123 (2017).

11. Chaturvedi, D. \& Mahalakshmi, R. Transmembrane beta-barrels: Evolution, folding and energetics. Biochim Biophys. Acta Biomembr. 1859, 2467-2482 (2017).

12. Kim, J., Na, Y. J., Park, S. J., Baek, S. H. \& Kim, D. H. Biogenesis of chloroplast outer envelope membrane proteins. Plant Cell Rep. 7, 783-792 (2019).

13. Noinaj, N., Gumbart, J. C. \& Buchanan, S. K. The beta-barrel assembly machinery in motion. Nat. Rev. Microbiol 15, 197-204 (2017).

14. $\mathrm{Wu}, \mathrm{T}$. et al. Identification of a multicomponent complex required for outer membrane biogenesis in Escherichia coli. Cell 121, 235-245 (2005).

15. Malinverni, J. C. et al. YfiO stabilizes the YaeT complex and is essential for outer membrane protein assembly in Escherichia coli. Mol. Microbiol 61, 151-164 (2006)

16. Voulhoux, R., Bos, M. P., Geurtsen, J., Mols, M. \& Tommassen, J. Role of a highly conserved bacterial protein in outer membrane protein assembly. Science 299, 262-265 (2003)

17. Baud, C. et al. Translocation path of a substrate protein through its Omp85 transporter. Nat. Commun. 5, 5271 (2014).

18. Hohr, A. I. C. et al. Membrane protein insertion through a mitochondrial beta-barrel gate. Science 359, eaah6834 (2018).

19. Bakelar, J., Buchanan, S. K. \& Noinaj, N. The structure of the beta-barrel assembly machinery complex. Science 351, 180-186 (2016).

20. Gu, Y. et al. Structural basis of outer membrane protein insertion by the BAM complex. Nature 531, 64-69 (2016).

21. Iadanza, M. G. et al. Lateral opening in the intact beta-barrel assembly machinery captured by cryo-EM. Nat. Commun. 7, 12865 (2016).

22. Noinaj, N., Kuszak, A. J., Balusek, C., Gumbart, J. C. \& Buchanan, S. K. Lateral opening and exit pore formation are required for BamA function. Structure 22, 1055-1062 (2014).

23. Hartmann, J. B., Zahn, M., Burmann, I. M., Bibow, S. \& Hiller, S. Sequencespecific solution NMR assignments of the beta-barrel insertase bama to monitor its conformational ensemble at the atomic level. J. Am. Chem. Soc. 140, 11252-11260 (2018)

24. Noinaj, N. et al. Structural insight into the biogenesis of beta-barrel membrane proteins. Nature 501, 385-390 (2013).

25. Lundquist, K., Bakelar, J., Noinaj, N. \& Gumbart, J. C. C-terminal kink formation is required for lateral gating in BamA. Proc. Natl Acad. Sci. USA 115, E7942-E7949 (2018).

26. Doerner, P. A. \& Sousa, M. C. Extreme dynamics in the BamA beta-barrel seam. Biochemistry 56, 3142-3149 (2017).

27. Ieva, R. \& Bernstein, H. D. Interaction of an autotransporter passenger domain with BamA during its translocation across the bacterial outer membrane. Proc. Natl Acad. Sci. USA 106, 19120-19125 (2009).

28. Ieva, R., Skillman, K. M. \& Bernstein, H. D. Incorporation of a polypeptide segment into the beta-domain pore during the assembly of a bacterial autotransporter. Mol. Microbiol 67, 188-201 (2008). 
29. Lee, J. et al. Characterization of a stalled complex on the beta-barrel assembly machine. Proc. Natl Acad. Sci. USA 113, 8717-8722 (2016).

30. Pavlova, O., Peterson, J. H., Ieva, R. \& Bernstein, H. D. Mechanistic link between beta barrel assembly and the initiation of autotransporter secretion. Proc. Natl Acad. Sci. USA 110, E938-E947 (2013).

31. Sikdar, R., Peterson, J. H., Anderson, D. E. \& Bernstein, H. D. Folding of a bacterial integral outer membrane protein is initiated in the periplasm. Nat. Commun. 8, 1309 (2017).

32. Wzorek, J. S., Lee, J., Tomasek, D., Hagan, C. L. \& Kahne, D. E. Membrane integration of an essential beta-barrel protein prerequires burial of an extracellular loop. Proc. Natl Acad. Sci. USA 114, 2598-2603 (2017).

33. Gessmann, D. et al. Outer membrane beta-barrel protein folding is physically controlled by periplasmic lipid head groups and BamA. Proc. Natl Acad. Sci. USA 111, 5878-5883 (2014).

34. Hussain, S. \& Bernstein, H. D. The Bam complex catalyzes efficient insertion of bacterial outer membrane proteins into membrane vesicles of variable lipid composition. J. Biol. Chem. 293, 2959-2973 (2018).

35. Albenne, C. \& Ieva, R. Job contenders: roles of the beta-barrel assembly machinery and the translocation and assembly module in autotransporter secretion. Mol. Microbiol 106, 505-517 (2017).

36. Ieva, R., Tian, P., Peterson, J. H. \& Bernstein, H. D. Sequential and spatially restricted interactions of assembly factors with an autotransporter beta domain. Proc. Natl Acad. Sci. USA 108, E383-E391 (2011).

37. Peterson, J. H., Tian, P., Ieva, R., Dautin, N. \& Bernstein, H. D. Secretion of a bacterial virulence factor is driven by the folding of a C-terminal segment. Proc. Natl Acad. Sci. USA 107, 17739-17744 (2010).

38. Kang'ethe, W. \& Bernstein, H. D. Charge-dependent secretion of an intrinsically disordered protein via the autotransporter pathway. Proc. Natl Acad. Sci. USA 110, E4246-E4255 (2013).

39. Skillman, K. M., Barnard, T. J., Peterson, J. H., Ghirlando, R. \& Bernstein, H. D. Efficient secretion of a folded protein domain by a monomeric bacterial autotransporter. Mol. Microbiol 58, 945-958 (2005).

40. Barnard, T. J., Dautin, N., Lukacik, P., Bernstein, H. D. \& Buchanan, S. K. Autotransporter structure reveals intra-barrel cleavage followed by conformational changes. Nat. Struct. Mol. Biol. 14, 1214-1220 (2007).

41. Roman-Hernandez, G., Peterson, J. H. \& Bernstein, H. D. Reconstitution of bacterial autotransporter assembly using purified components. eLife 3, e04234 (2014).

42. Barnard, T. J. et al. Molecular basis for the activation of a catalytic asparagine residue in a self-cleaving bacterial autotransporter. J. Mol. Biol. 415, 128-142 (2012).

43. Cardona, S. T. \& Valvano, M. A. An expression vector containing a rhamnoseinducible promoter provides tightly regulated gene expression in Burkholderia cenocepacia. Plasmid 54, 219-228 (2005).

44. Robert, V. et al. Assembly factor Omp85 recognizes its outer membrane protein substrates by a species-specific C-terminal motif. PLoS Biol. 4, e377 (2006).

45. Walther, D. M., Bos, M. P., Rapaport, D. \& Tommassen, J. The mitochondrial porin, VDAC, has retained the ability to be assembled in the bacterial outer membrane. Mol. Biol. Evol. 27, 887-895 (2010).

46. Rigel, N. W., Ricci, D. P. \& Silhavy, T. J. Conformation-specific labeling of BamA and suppressor analysis suggest a cyclic mechanism for betabarrel assembly in Escherichia coli. Proc. Natl Acad. Sci. USA 110, 5151-5156 (2013).

47. Pinto, C. et al. Formation of the beta-barrel assembly machinery complex in lipid bilayers as seen by solid-state NMR. Nat. Commun. 9, 4135 (2018).

48. Gruss, F. et al. The structural basis of autotransporter translocation by TamA. Nat. Struct. Mol. Biol. 20, 1318-1320 (2013).

49. Bay, D. C., Hafez, M., Young, M. J. \& Court, D. A. Phylogenetic and coevolutionary analysis of the beta-barrel protein family comprised of mitochondrial porin (VDAC) and Tom40. Biochim Biophys. Acta 1818, 1502-1519 (2012)

50. Robinson, J. A. Folded synthetic peptides and other molecules targeting outer membrane protein complexes in Gram-negative bacteria. Front Chem. 7, 45 (2019).

51. Peterson, J. H., Plummer, A. M., Fleming, K. G. \& Bernstein, H. D. Selective pressure for rapid membrane integration constrains the sequence of bacterial outer membrane proteins. Mol. Microbiol 106, 777-792 (2017).

52. Franklin, M. W. et al. Evolutionary pathways of repeat protein topology in bacterial outer membrane proteins. eLife 7, e40308 (2018).

53. Szabady, R. L., Peterson, J. H., Skillman, K. M. \& Bernstein, H. D. An unusual signal peptide facilitates late steps in the biogenesis of a bacterial autotransporter. Proc. Natl Acad. Sci. USA 102, 221-226 (2005).

54. Lomize, M. A., Pogozheva, I. D., Joo, H., Mosberg, H. I. \& Lomize, A. L. OPM database and PPM web server: resources for positioning of proteins in membranes. Nucleic Acids Res 40, D370-D376 (2012).

\section{Acknowledgements}

We would like to thank Janine Peterson for technical assistance in the subcloning of malE and Sunyia Hussain for critical reading of the paper. This work was supported by the Intramural Research Program of the National Institute of Diabetes and Digestive and Kidney Diseases.

\section{Author contributions}

The study was conceived and designed by M.T.D. and H.D.B. The experimental work was conducted by M.T.D. The paper was written by M.T.D. and H.D.B.

\section{Additional information}

Supplementary Information accompanies this paper at https://doi.org/10.1038/s41467019-11230-9.

Competing interests: The authors declare no competing interests.

Reprints and permission information is available online at http://npg.nature.com/ reprintsandpermissions/

Peer review information: Nature Communications thanks the anonymous reviewers for their contribution to the peer review of this work. Peer reviewer reports are available.

Publisher's note: Springer Nature remains neutral with regard to jurisdictional claims in published maps and institutional affiliations.

Open Access This article is licensed under a Creative Commons Attribution 4.0 International License, which permits use, sharing, adaptation, distribution and reproduction in any medium or format, as long as you give appropriate credit to the original author(s) and the source, provide a link to the Creative Commons license, and indicate if changes were made. The images or other third party material in this article are included in the article's Creative Commons license, unless indicated otherwise in a credit line to the material. If material is not included in the article's Creative Commons license and your intended use is not permitted by statutory regulation or exceeds the permitted use, you will need to obtain permission directly from the copyright holder. To view a copy of this license, visit http://creativecommons.org/ licenses/by/4.0\%

This is a U.S. government work and not under copyright protection in the U.S.; foreign copyright protection may apply 2019 